This item was submitted to Loughborough's Research Repository by the author.

Items in Figshare are protected by copyright, with all rights reserved, unless otherwise indicated.

\title{
Testing 3D landform quantification methods with synthetic drumlins in a real digital elevation model
}

PLEASE CITE THE PUBLISHED VERSION

http://dx.doi.org/10.1016/j.geomorph.2012.02.009

PUBLISHER

(c) 2012 Elsevier B.V.

VERSION

AM (Accepted Manuscript)

LICENCE

CC BY-NC-ND 4.0

REPOSITORY RECORD

Hillier, John K., and Mike J. Smith. 2019. "Testing 3D Landform Quantification Methods with Synthetic Drumlins in a Real Digital Elevation Model”. figshare. https://hdl.handle.net/2134/13010. 
This item was submitted to Loughborough's Institutional Repository (https://dspace.lboro.ac.uk/) by the author and is made available under the following Creative Commons Licence conditions.

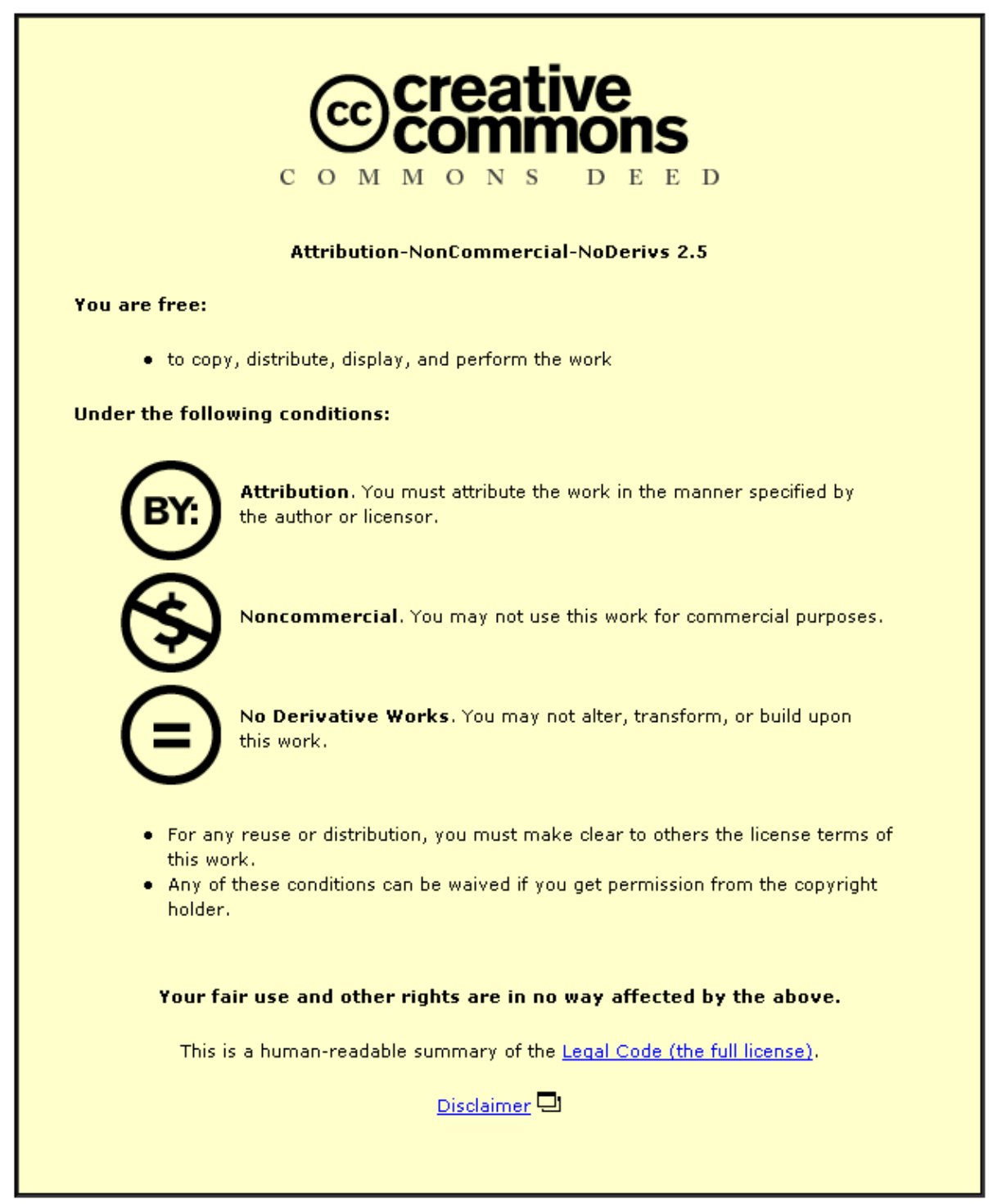

For the full text of this licence, please go to: http://creativecommons.org/licenses/by-nc-nd/2.5/ 
1 Testing 3D landform quantification methods with synthetic drumlins in a real digital

2 elevation model

3

4 J. K. Hillier ${ }^{\mathrm{a}^{*}}$ and M. J. Smith ${ }^{\mathrm{b}} \quad{ }^{*}$ Corresponding Author

$5 \quad{ }^{a}$ Department of Geography, Loughborough University, LE11 3TU, UK. j.hillier@lboro.ac.uk.

6 tel: $0044(0) 1509223727$ fax: $0044(0) 1509223930$

$7 \quad{ }^{\mathrm{b}}$ School of Geography, Earth and the Environment, Kingston University, KT1 2EE, UK.

8 mike@hsm.org.uk

Metrics such as height and volume quantifying the 3D morphology of landforms are important

11 observations that reflect and constrain Earth surface processes. Errors in such measurements are,

12 however, poorly understood. A novel approach, using statistically valid 'synthetic' landscapes to

13 quantify the errors is presented. The utility of the approach is illustrated using a case study of

14184 drumlins observed in Scotland as quantified from a Digital Elevation Model (DEM) by the

15 'cookie cutter' extraction method. To create the synthetic DEMs, observed drumlins were

16 removed from the measured DEM and replaced by elongate 3D Gaussian ones of equivalent

17 dimensions positioned randomly with respect to the 'noise' (e.g. trees) and regional trends (e.g.

18 hills) that cause the errors. Then, errors in the cookie cutter extraction method were investigated

19 by using it to quantify these 'synthetic' drumlins, whose location and size is known. Thus, the

20 approach determines which key metrics are recovered accurately. For example, mean height of

$216.8 \mathrm{~m}$ is recovered poorly at $12.5 \pm 0.6(2 \sigma) \mathrm{m}$, but mean volume is recovered correctly.

22 Additionally, quantification methods can be compared: A variant on the cookie cutter using an

23 un-tensioned spline induced about twice $(\times 1.79)$ as much error. Finally, a previously reportedly

24 statistically significant $(p=0.007)$ difference in mean volume between sub-populations of

25 different ages, which may reflect formational processes, is demonstrated to be only 30-50\%

26 likely to exist in reality. Critically, the synthetic DEMs are demonstrated to realistically model

27 parameter recovery, primarily because they are still almost entirely the original landscape. 
Results are insensitive to the exact method used to create the synthetic DEMs, and the approach could be readily adapted to assess a variety of landforms (e.g. craters, dunes, volcanoes).

Key words: synthetic, landform, DEM, drumlin, volume

\section{Introduction}

The 3D properties of landforms record information about the processes that formed them (e.g. Evans, 1987; Rose, 1989; Marova, 2002). Specifically, drumlins' heights, $H$, and volumes, $V$, may preserve information about the dynamics of former ice sheets (e.g. Smith et al., 2009). Quantification of these metrics (e.g. Smith et al., 2009), however, is prone to inaccuracy in the presence of topographic 'noise' (e.g. trees, post-formational erosion) and underlying larger-scale slopes (e.g. hills). So, observations like recovered mean height $\left(\bar{H}_{r}\right)$ might be substantially overestimated and reflect noise rather than ice sheet processes. Without precise, accurate and reliable observations scientific conclusions based upon them must remain in some doubt. A fundamental question then arises of how to test quantification methods. What is the correct answer to test against? Like many classes of landform, the geometric rules used to map drumlins (e.g. Shaw, 1983; Rose, 1987; Smith and Clark, 2005; Clark et al., 2009; Spagnolo et al., 2010) are not yet definitively defined. So, establishing an objective a priori correct ground-truth with which to test the quantitative methods is not possible. It is not possible to conduct a careful manual interpretation, or an analysis using visually assessed numerical methods, and claim this as to be the 'correct' $H$ or $V$. Either would just be one estimate, based on a number of implicit or explicit assumptions. Subsequent tests to determine which computational method best reproduced these 'correct' values would then simply indicate the method that best reproduced the underlying subjective preferences. This can, and has (e.g. Hillier, 2008), been done but is not a truly objective assessment. In these circumstances it is standard best-practice to test the method 
with some idealised or 'synthetic' data such as the classic 'synthetic checkerboard' test (e.g. Dziewonski et al., 1977, Saygin and Kennett, 2010) used extensively in Earth tomography. The constituent stages of this test (Nolet et al., 2007) illustrate the key elements of a synthetic test

1. Construct a synthetic input, which should include the feature of interest. In geomorphology, this could be the expected morphology of a landform.

2. Create synthetic data that resembles the observed data, with suitable noise added. In geomorphology, this could be a DEM including the synthetic input.

3. Invert synthetic data using the same numerical method applied to the observed data

4. Compare inverted result with the synthetic input to see how well the assumed synthetic input (e.g. landform) is recovered.

In geomorphology, synthetic data have been used to assess numerical methods for estimating the fractal dimension of topography (Malinverno, 1989; Tate, 1998a,b), and slope and aspect (Zhou, 2004). The performance of filters intended to isolate submarine volcanoes has also been assessed by simplistically approximating them as cones on planar surfaces (Wessel, 1998; Hillier, 2008; Kim and Wessel, 2008). Realistic 'noise' and regional trends, however, have not been used to assess landform retrieval. Neither have methods to extract the 3D properties (e.g. height and volume) of other landforms yet been subject to testing with synthetic DEMs. The difficulty lies in generating a suitable, statistically representative synthetic landscape.

Synthetic DEMs may be constructed by i) using simple geometries as building blocks such as cones or planes (e.g. Wessel, 1997; Kim and Wessel, 1998; Zhou, 2004; Hillier, 2008) ii) generated statistically using fractals (e.g. Mandelbrot, 1983) or multi-fractals (e.g. Gilbert, 1989; Weissel, 1994; Cheng, 1996) or iii) created by the application of mathematical descriptions of physical processes in 'landscape evolution models' (e.g. Chase, 1992; Braun and Sambridge, 1997). Synthetic DEMs created using simple building blocks, do not contain the complexity in 
the observed landscape, or necessarily have realistic statistical properties. Even multi-fractal landscapes, may not have correct statistics without considering properties such as anisotropy (e.g. Gagon, 2006) and characteristic scales (e.g. Perron, 2008), but more importantly these DEMs will not contain spatially distinct, isolated features (e.g. drumlins). Landscape evolution models, which link form with process by applying mathematically characterisations of the processes, can now incorporate many processes (Tucker, 2010); for instance, stochastic bedrock landsliding (e.g. Densmore, 1998), flexural isostasy (e.g. Lane et al., 2008), and valley-scale erosion by ice flow (e.g. Harbour, 1992; Brocklehurst and Wipple, 2004; Amundson and Iverson, 2006; Tomkin, 2009), including under thermo-mechanically coupled 3D ice sheets (e.g. Jamieson et al., 2008). Numerical models, however, cannot as yet realistically generate some landforms such as drumlins (e.g. Hindmarsh, 1998; Schof, 2007; Fowler, 2000, 2009, 2010a, 2010b). The problem of creating a statistically representative synthetic landscape containing drumlins therefore remains a current one.

By whichever method synthetic DEMs are generated, if they are to be used in the assessment of morphological mapping or to test numerical methods for quantifying the $3 \mathrm{D}$ properties of landforms, a number of criteria must be satisfied. Firstly, the synthetic DEM must be quantitatively representative of the observed landscape, at least in the aspects of it being examined. This is necessary to comment upon process-related statements such as 'landform subpopulation A differs from sub-population B'. Synthetics partially reflecting the observed landscape will permit only a subset of inferences to be drawn. Of particular note is the difficulty of 'noise' (e.g. alignments of trees). Noise may not be well represented by statistical noise (e.g. Lombardini, 2005; Jordan and Watts, 2005; Sun, 2009) and its removal by 'decluttering' (e.g. Sithole and Vosselman, 2004) likely distorts the landforms. The second criterion is that circularity, the retrieval of input assumptions, must be avoided. For instance, synthetic DEMs should not contain signatures of any isolation method such as the cookie cutter that would cause it to be favoured when comparing isolation methods. 
110 This paper proposes a method of testing 3D landform quantification techniques such as the

111 cookie cutter. It is applicable to varied study areas without substantial customization, and is

112 potentially applicable to various landforms (e.g. drumlins, dunes, scoria cones, landslides). It

113 avoids a priori assumptions about process and permits analyses of synthetics that are directly

114 and securely relevant to real study sites. These assertions are demonstrated using a worked

115 example. The study area, DEM data and quantification method used are outlined in Section 2.

116 The processes of creating and using the synthetic DEMs (Fig. 1) has four stages, listed below,

117 corresponding to those enumerated above. These stages are explained sequentially in the paper.

1. To first-order isolate, remove, and parameterise landforms (i.e. drumlins) from the measured DEM (Sections 3.1 and 3.2). Then, establish their idealised 3D shape (Section

$$
3.3) \text {. }
$$

2. Re-insert idealised landforms (i.e. drumlins) using parameters matching those removed into the 'synthetic' DEMs at locations that are random with respect to surface clutter and larger features (Section 3.4).

3. Run the quantification methodology under examination, i.e. the cookie cutter (Section 4)

Some ways in which observations and scientific claims may be evaluated using synthetic DEMs are then illustrated through the worked example, assessing the 'cookie cutter' method of Smith et al. (2009) as applied to the drumlin field they analysed in central Scotland. The same DEM and manual digitisations of the drumlins' outlines are used so that a direct comparison is possible. To highlight the extent of the observational problem note that it is not known if important

133 parameters, e.g. recovered mean volume $\left(\bar{V}_{r}\right)$, reflect the actual population at all. 
137 The study area is in the western part of central Scotland (Fig. 2a). It (Fig. 2c) is $13 \times 8 \mathrm{~km}$ in 138 size, is identical to that analysed by Smith et al. (2009), and completely contains 175 landforms

139 interpreted by them as drumlins. These landforms are Younger Dryas (YD) [ 12 ka] and Last

140 Glacial Maximum (LGM) [ 20 ka] in age (Rose and Smith, 2008). Smith et al. (2009) report

141 that, using a t-test without assuming equal variances, the observed difference in mean volumes

142 between YD and LGM drumlins is statistically significant. Specifically, this refers to a

143 difference in the logarithms of volumes, $\Delta \overline{\ln (V)}$, calculated as $\overline{\ln (V)}_{L G M}-\overline{\ln (V)}_{Y D}$.

As in Smith et al. (2009) the NEXTmap Britain ${ }^{\mathrm{TM}}$ digital surface model (DSM), or 'NEXTmap',

146 is used in this study (Fig. 2b). NEXTmap is a single-pass interferometric synthetic aperture

147 radar (IfSAR) product presented as a spatial $(x, y)$ grid at a resolution of five metres, with a

148 vertical resolution estimated as 0.5-1 m (Intermap, 2004). The 184 digitised drumlin outlines

149 used are also those of Smith et al. (2009) (Fig. 2c). These were digitised from NEXTmap and

150 quantitatively compared to field mapping in Smith et al. (2006). A combination of gradient, two

151 orthogonal relief-shaded images, and local contrast visualizations, considered 'optimal' (Smith

152 and Clark, 2005), was used in the digitisation to minimise bias in the orientations of the drumlins

153 (Smith and Wise, 2007). Re-analysis of the digitised outlines of the 184 drumlins indicates that

154178 drumlins $(n=178)$ have all vertices within the study area, and these are used as the basis for

155 computation in this paper based on this criterion alone.

157 The semi-automated 'cookie cutter' method (Smith et al., 2009) estimates a basal surface by 158 interpolating between points on manually digitised drumlins' outlines using a fully tensioned 159 (i.e. $\mathrm{T}=1$ ) bi-cubic spline (e.g. Smith and Wessel, 1990), thereby permitting drumlins' volumes

$160(V)$ and maximum heights $(H)$ to be estimated. Specifically, this is implemented here by

161 considering each drumlin in turn, starting from complete data across a sub-region of the observed 
163

using the spline to estimate a basal surface, and finally iii) calculating $H$ and $V$. $H$ is the

164 maximum vertical difference between the original and interpolated surfaces, and $V$ as the volume between the surfaces. All calculations are at the full resolution of the DEM.

166

\section{$\underline{3.1 \text { Drumlin isolation and removal }}$}

\section{Method for creating the synthetic DEMs}

This section describes the methods used during the steps to create the synthetic DEMs, which are outlined in Section 1.

Height, $H$, recorded in Digital Elevation Models (DEMs) can be described at any location $(x, y)$ as the sum of $n$ 'components' (Eq. 1) (e.g. Wren, 1973; Wessel, 1998; Hillier and Watts, 2004; Hillier and Smith, 2008).

The topography of the study area can be described by Eq. 2, where 'noise' consists of surface 'clutter'; small-scale height variations not genetically related to drumlin formation. Specifically, clutter includes features such as trees and houses resting upon the terrain, and post-glacial 
alterations. 'hills' is a shorthand for larger-scale trends and landforms that are not drumlins.

191 Regional-residual separation into these components is conducted using two standard (e.g.

192 Wessel, 1998) sliding-window median filters. This filter is chosen for its robustness to outliers, simplicity, so that no element of the cookie cutter method was involved in the creation of the synthetic DEMs. This was done to avoid any possibility of circularity.

Numerous inspections, such as that illustrated in Figs. 3 and $4 \mathrm{a}, \mathrm{b}$, were used to establish the best filter widths $(60 \mathrm{~m}, 500 \mathrm{~m})$ for this initial estimate of drumlins' 3D form. Note, however that it is not possible to objectively demonstrate that any RRS is optimal at this stage because no 'correct' interpretation is known to test against. The efficacy of the division into the three components is illustrated as follows: Drumlins are not visible in Fig. 3c, clutter is minimized in Fig. 3b, and drumlins are not visible in $H_{\text {hills }}$ (Fig. 3d). Even for this best visual assessment, some undesirable behaviours still exist. For example, the basal surface estimated is higher than might be expected in places (Fig. 4a,b). The synthetic DEMs created using the filters selected, however, are shown to be sufficiently realistic in Section $6 ; H$ and $V$ are extracted in the same way for the real and synthetic DEMs.

$H_{\text {drumlins }}$ was subtracted from $H_{\text {DEM }}$ within the digitised outlines to remove drumlins, but they will be replaced by similar objects within the landscape (Fig. 1, Section 3.4). Outside the digitized outlines the DEM was not altered, retaining all its spatial and statistical characteristics. Thus, the synthetic landscapes will closely resemble the original.

\subsection{Drumlin parameterisation}

214 Length $(L)$, width $(W)$, height $(H)$, and volume $(V)$ are the main parameters used to quantify 215 drumlins. $L-W-H$ triplets are needed to create idealised drumlins for the synthetic DEMs. $L$ and $216 W$ are properties of drumlins' planform shapes, but can be calculated several different ways. 
217 Since drumlins' idealised planar shape remains debated (e.g. Corley, 1959; Shaw, 1983;

218 Spagnolo et al., 2010), methods assuming an idealised shape are not used here. Instead, $L$ and $W$ 219 are calculated directly from drumlins' manually digitised outlines. Errors and systematic baises 220 due to any method chosen for this, and then to calculate $H$ and $V$, are unavoidable. So, two 221 contrasting methods were implemented (Appendix A) so that the sensitivity of parameters $\left(\theta_{L}, V\right.$, $H, L$, and $W$ ) to them can be assessed. These are referred to as 'Method 1' and 'Method 2'.

\subsection{Representative 3D drumlin shape}

Using an idealised shape for drumlins breaks the link between filters used to generate input $H$ and $V$ and the testing of recovery efficacy. Without this break some signature of these filters may remain, perhaps introducing circularity. What shape, however, is appropriate?

Drumlins can be described as 'an elongated hill or mound ... possessing a smooth "moulded" outline' (Hollingsworth, 1931), and various analogies have been used to describe their geometry: e.g. half torpedo, tear drop, half egg, cigar (see Spagnolo, 2010). Shaw (1983) distinguishes three isolate forms, i.e. those not in contact with other forms: 'spindle', 'parabolic', and 'transverse asymmetrical'. Reed et al. (1962), however, remain alone in proposing a 3D form with a simple mathematical description, the ellipsoid. In ellipsoids, slopes increase towards their edges. This model does not fit in the Central Scotland study area where slopes appear to decrease (Fig. 4a,b).

To determine a representative $3 \mathrm{D}$ drumlin shape to use in creating synthetic landscapes transverse and longitudinal profiles from the drumlins were stretched to a standard size and overlain on each other i.e., de-cluttered, de-trended, normalised (Fig. 4c,d), and stacked (Fig. 5).

242 To de-trend, the estimated basal surface was subtracted. To normalize, distances were linearly 243 scaled such that $L, W$, and $H$ all become 1.0. To stack, the mean and standard deviation of 
normalized heights at each normalized distance along the profile were computed. Note that all profiles start from $\theta_{L}$ (Fig. 6a) used so the longitudinal profiles all align, with $C_{\mathrm{xy}}$ to the right.

Visually, a Gaussian form (grey line) well approximates the average transverse profiles (Fig.

5 b,d), i.e. is within $\pm 2 \sigma_{\bar{H}}$, and is close to the longitudinal profile of Method 1. In accord with

249 observations elsewhere (Spagnolo et al., 2010) the asymmetries for Method 2 are not strongly

250 aligned with flow (Fig. 2c), and so Fig. 5c resembles Fig. 5a if drumlins are aligned to the

251 interpreted regional flow direction before stacking. About $10 \%$ of the height change associated

252 with the approximating Gaussians' amplitude is outside the grey box representing the drumlins'

253 limits (Fig. 5). So, the upper $90 \%$ of an elongate Gaussian form (Fig. 7), $H_{f}=0.9$, is taken as the

254 representative 3D form for drumlins in this study area. Are the stacked profiles exactly

255 Gaussian? Points along the observed curves (black lines) lack independence, rendering

256 statistical tests (e.g. Chi-squared goodness of fit) of this invalid, but the question is also not

257 particularly relevant. As above, the approximation is demonstrably sufficient because $H$ and $V$

258 are extracted in the same way for the real and synthetic DEMs. Reassuringly, volumes of

259 idealised Gaussians (Eq. A.1, Fig. 7) and volumes from grid-based calculations, for Method 2

260 where direct comparison is possible, agree well visually (Fig. 8b) and correlate with an $r^{2}=$

$2610.8724(n=173)$. So, the Gaussian approximation has no systematic effect upon input volumes, $262 V_{\text {in }}$.

\subsection{Building synthetic DEMs}

Using an idealised Gaussian shape (Appendix B), and parameters characterising the drumlins

267 (Fig. 8), synthetic DEMs were created by removing existing drumlins and inserting idealised 268 ones (Fig. 1). To avoid the non-trivial problem of statistically generating realistic $H-W-L$ triplets 269 the measured ones where $H>0$ were used; $n=178$ for Method 1 and $n=173$ Method 2. 
Complications avoided include i) the relative abundances of different sizes of $L, W, H$ (Fig. $8 \mathrm{c}, \mathrm{d}, \mathrm{e})$ and ii) the strength of correlations between $L-W, L-H$ and $H-W$ varying as a function of size. The spatial distribution of drumlins (Fig. 9a,b) was reproduced (Fig. 9 c,d), and the distribution of $\theta_{L}$ was replicated (Fig. 8a). Details of the exact procedures used are in Appendix C. For both Method 1 and Method 210 synthetic DEMs and sets of digital drumlin outlines, were created. It would also be possible to spatially vary the dominant orientation, making the synthetic more realistic. However, when analysed, $H$ and $V$ are extracted in the same way for the real and synthetic DEMs (Section 6). So neither this additional complexity, nor the inclusion of asymmetry in an idealised Gaussian shape, is necessary.

\section{Method for using the synthetic DEMs to assess the cookie cutter}

This section describes the methods used to interrogate the synthetic DEMs. To assess its ability to recover $H$ and $V$, the cookie cutter was applied to each of the 20 synthetic landscapes. The heights and volumes of the idealised drumlins put into the synthetic DEMs are denoted $H_{\text {in }}$ and $V_{i n}$. Recovered heights are denoted, $H_{r}$, and volumes, $V_{r}$. In addition, analyses were repeated employing a variant of the cookie cutter method, using an un-tensioned (i.e. $\mathrm{T}=0$ ) rather than a tensioned (i.e. $\mathrm{T}=1$ ) spline. This test is designed to illustrate the utility of synthetic DEMs in assessing different extraction methodologies. The results of both tests are reported in Sections 5.1 to 5.3. Note that, for consistency, the same parameterisation method (e.g. Method 1) was used to quantify drumlins extracted by the cookie cutter as was used to create the synthetic DEM analysed.

Next, the types of investigation made possible by knowing both $V_{i n}$ and $V_{r}$ for synthetic DEMs are illustrated. Their results are reported in Section 5.4. The first illustrative investigation assesses the likelihood that the difference in volume between YD and LGM drumlins reported by Smith et al. (2009) actually exists when errors that occur during the extraction of drumlins' 
297

volumes are considered. Standard statistical tests (e.g. Smith et al. 2009) implicitly assume that automated methods recover drumlins' parameters exactly. A sub-set of 100,000 stochastically generated pairs of LGM and YD sub-populations with 'observed' differences (i.e. $\Delta \overline{\ln \left(V_{r}\right)}$ ) extracted by the cookie cutter more extreme than that reported by Smith et al. (2009) was assessed to see what proportion of them had 'real' input differences (i.e. $\left.\Delta \overline{\ln \left(V_{i n}\right)}\right)$ over the threshold for $95 \%$ significance (i.e. $\Delta \overline{\ln (V)}_{\text {crit }}$ ). To paraphrase; If the difference you extract is at least as large as that reported by Smith et al. (2009), what fraction of the time is the actual difference large enough to be statistically significant? This is illustrated in Fig. 10, with details of the stochastic modelling in Appendix D.

A second investigation was also performed. It is possible that the observed $\Delta \bar{V}$ between subpopulations is due to how the cookie cutter method interacts with spatial variation in regional trends and topographic noise between the LGM and YD regions. This was tested. If the recovered difference in mean volumes between regions is consistently larger or smaller than that input, this is caused by a difference between them. The effect, $E$, that the process of landform extraction makes to the difference in mean volume between the LGM and YD areas (i.e. $\bar{V}_{L G M}-\bar{V}_{Y D}$ ), was quantified as the change in difference between average volumes of the subpopulations between input and recovery, specifically

Eq. (3) $\quad E_{V}=\frac{1}{n} \sum_{i=1}^{n}\left(\Delta \bar{V}_{r}-\Delta \bar{V}_{i n}\right)_{i}$

where $i$ is the number of the DEM out of 10. $\Delta \bar{V}_{r}$ and $\Delta \bar{V}_{i n}$ are retrieved and input volume differences respectively. Equivalent comparisons were made for $\Delta \bar{H}$, un-tensioned splines, and Methods 1 and 2.

\section{Results}

\section{$\underline{5.1 \text { Negative volumes }}$}


324 For the 10 synthetic DEMs analysed using the cookie cutter and parameterised with Method 1, $32514.3 \pm 6.4(2 \sigma)$ of 178 drumlins have negative (i.e. incorrect) volumes. For Method 2 the 326 equivalent number is similar, $15.4 \pm 2.8(2 \sigma)$ of 173 . Within error these are not distinguishable

327 from the 11 negative volumes recovered by analysing the original DEM and its manually 328 digitised outlines. This is a first indicator that the synthetic DEMs well replicate the original, at 329 least when measuring $H$ and $V$. Using an un-tensioned spline figures are $32.3 \pm 7.6(2 \sigma)$ and $33026.4 \pm 9.2(2 \sigma)$ for Methods 1 and 2 respectively. So, these definite errors are significantly more 331 numerous for the un-tensioned spline (e.g. $p=\sim 7 \times 10^{-10}$, Method 1, 1-tailed $t$-test assuming equal 332 variances). This is initial evidence that the un-tensioned variant recovers $H$ and $V$ more poorly. 333 Note that in hilly, noisy terrain large errors producing negative volumes are expected of 334 interpolation using splines (e.g. Fig 11 b of Smith et al. (2009)). Indeed, this is one of the main 335 drivers behind this work to develop synthetic DEMs.

\section{$\underline{5.2 \text { Individual heights and volumes }}$}

For Method 1 parameters, $39.2 \%$ of individual recovered volumes are within $\times 0.75-1.25$ of $V_{\text {in }}$,

340 i.e. $V_{r} / V_{\text {in }}$ is in the range 0.75 to 1.25 . Table 1 summarizes such results. Percentages are 341 consistently higher for $V$ than $H$, and for tensioned rather than un-tensioned variants for the 342 cookie cutter. Consistent with this, standard deviations of $V_{r} / V_{i n}$ are notably smaller for 343 tensioned as compared to un-tensioned splines, although this difference is much less marked for $344 H_{\mathrm{r}} / H_{\mathrm{in}}$. In short, on an individual basis drumlins' parameters are poorly recovered, especially for 345 the un-tensioned spline. $V_{r}$ values are distributed approximately symmetrically about their true 346 values i.e. $V_{\text {in }}$, whilst recovered heights tend to be too great (Fig. 11). This determines how well 347 population parameters are recovered (Section 5.3 ). The range $1 \pm 0.25$ is arbitrarily chosen, but 348 observations are consistent for other ranges e.g. $1 \pm 0.5$. Figure 11 plots the shape of the 
distributions of $V_{r} / V_{\text {in }}$ and $H_{\mathrm{r}} / H_{\text {in }}$, and illustrates that large drumlins (black) are recovered in a

350 similar way to the whole population. This is a necessary check that small, numerous drumlins

351 are not dominating the results.

\subsection{Population parameters}

For the 10 groups of 178 drumlins, of parameters estimated by Method 1, mean input volume $\left(\bar{V}_{\text {in }}\right)$ is $1.59 \times 10^{5} \mathrm{~m}^{3}$. Mean volume $\left(\bar{V}_{r}\right)$ is recovered well as $1.56 \pm 0.16 \times 10^{5} \mathrm{~m}^{3}(2 \sigma)$. The

$10 \bar{V}_{r}$ estimates are plotted in Figure $12 \mathrm{~b}$, and $\bar{V}_{\text {in }}$ is within the spread of these figures. Mean height $\left(\bar{H}_{\text {in }}\right)$ of $6.8 \mathrm{~m}$ is poorly recovered as $12.5 \pm 0.6(2 \sigma) \mathrm{m} . \bar{H}_{\text {in }}$ is not within the spread of $\bar{H}_{r}$. This is due to the strongly skewed distribution of errors for individual drumlins (Fig. 11 a,c). Results are similar for Method 2, and for both tensioned and un-tensioned splines (Table 2), and so the observations are robust.

\section{$\underline{5.4 \text { Sub-populations }}$}

What is the effect of inaccuracies due to the cookie cutter method upon the conclusions of Smith et al. (2009)? This is the first investigation of sub-populations. For synthetics using Method 1, 715 of 100,000 simulations have observed volume differences $\Delta \overline{\ln \left(V_{r}\right)}$ more extreme than those observed by Smith et al. (2009). Of these only $42 \%$ of these have 'actual' input volume differences that are significant (i.e $\Delta \overline{\ln \left(V_{\text {in }}\right)}>\Delta \overline{\ln (V)}_{\text {crit }}$ ). A duplicate analysis, but using Method 2, gives a value of $38 \%$. A comparison with parametric statistics demonstrates the confidence that it is possible to have in the stochastic modelling. When inaccuracies in extracting the volumes are not considered they agree well. Specifically $p$ values under $H_{0}$ : $\overline{\ln \left(V_{L G M}\right)}=\overline{\ln \left(V_{Y D}\right)}$ for a t-test that does not assume equal variances and the stochastic modelling 
376 What is the effect upon population parameters of possible differences in the character of noise or 377 hills between the two regions? This is the second investigation. Mean $E_{V}$ values for Methods 1 and 2 (Table 3) quantify the systematic difference between areas. These are smaller than the 32,199 $\mathrm{m}^{3}$ observed by Smith et al. (2009) or in the opposite direction. So, they cannot explain the observation of Smith et al. (2009), reassuringly suggesting that it is possible to see 381 geomorphic signal through the noise. This main result is insensitive to method used or tension 382 on the spline employed (Table 3 ). For height, in contrast, a systematic effect of $\sim 1 \mathrm{~m}$ appeared consistently increasing heights for LGM drumlins more. This would have to considered were any claims made about differences in mean heights: For the data of Smith et al. (2009) the mean height of LGM drumlins is $3.0 \mathrm{~m}$ greater than YD, with a critical difference of only $2.0 \mathrm{~m}$ at the 95\% confidence level calculated stochastically assuming accurate extraction.

\section{Discussion}

For a synthetic DEM to be useful, it must be statistically representative of the real DEM, at least

391 for the scenario to be assessed. In this case, the scenario is the quantification of $H$ and $V$ using

392 semi-automated methods. In the search for a best way of quantifying drumlins, by definition no a priori information is or can be available for parameters of the original, non-Gaussian drumlins

394 in the DEM. So, the best test possible is to compare the shapes of recovered parameter 395 populations (Fig. 13). For these to match closely either all stages of generating and processing 396 the synthetic DEMs are correct or any significant errors that exist within these stages must have 397 produced equal and opposite effects.

399 A number of attempts are made to falsify the idea that the synthetic DEMs well approximate the 400 real landscape by comparing output from the cookie cutter method as applied to the original and 401 synthetic DEMs. Firstly, the shapes of the populations of recovered volumes are examined 
quantitatively by inter-quartile ranges and skews, and visually (Fig. 13a). They are very similar. Thus, the idea that the synthetic DEMs well represent reality is not contradicted. Secondly, the shape of an input $V$ distribution is modified, spread out, by errors in recovery (e.g. Fig. 13c). Similar numbers of negative volumes (Section 5.1), definite mistakes, for the real and synthetic datasets are therefore a strong direct indicator that DEMs are behaving similarly. Differences in the input distributions generated by Methods 1 and 2 (Fig. 8b), however, make this comparison inexact. The differences can, however, be corrected for by aligning mean recovered volumes $\left(\bar{V}_{r}\right)$ (Fig. 13a). This is valid if errors in recovery are randomly distributed about their true values, as they appear to be (Fig. 11b,d). Thus if errors are random, if input distributions (e.g. Fig. 8b) are of the correct shape, and if parameters are recovered in the same way for the real and synthetic data, scaled curves for recovered volumes should overlie each other. They do (Fig. 13a). 'Scaling factors', are 0.82 and 1.17 for Methods 1 and 2 respectively. Thus, the idea that the synthetic DEMs well represent reality is again not contradicted. It is not obvious, however, that a combination of a different 'scaling factor' and errors of a different magnitude may be able to equally well approximate the shape of the distribution. So, thirdly, to discount the possibility that the fit occurred by chance due to a trade-off between effects, an inversion (Fig. 13b) was conducted. This examined all possible magnitudes of scaling factor and error magnitude as multiples of that actually found for the synthetic data: 'error multiplier'. Best-fit scaling factors of 0.82 and 1.14 were found for Methods 1 and 2, very similar to those used to align the means. Thus the fit between the curves does not appear arbitrary. The error multipliers, applied to $V_{\mathrm{in}}-V_{\mathrm{r}}$ for individual drumlins that minimise misfit are 0.80 and 0.99 for Methods 1 and 2 respectively. These are again consistent with the idea that the synthetic DEMs well approximate reality, providing little evidence that results cannot be interpreted with confidence. An error multiplier of 0.80 suggests that analyses based on Method 1 may have errors that are $\sim 20 \%$ too large, but this is affects results insufficient to alter any conclusions. 
As for $V$, recovered $H$ distributions are of similar shape when aligned using mean values for the populations. The similarity, however, is less good, and no negative heights exist for comparison. So, analysis is less straightforward. Furthermore, due to the likely asymmetrical distribution of errors (Fig. 11a,c), the errors spread out the input distribution but also increase heights as can be done by a scaling factor. Misfit functions from an inversion therefore contain a trade-off, not a minimum as for $V$. However, using the misfit surface, the following can be stated. Firstly, if errors in the recovery of height (Fig. $11 \mathrm{a}, \mathrm{c}$ ) are correct, $H_{\text {in }}$ values need to be multiplied by $\sim 0.7$ for both Methods 1 and 2 in order to achieve a best fit. Namely, input heights are overestimated by $\sim 40 \%$. An alternative would be to assume that heights, $H_{\text {in }}$, are correct and errors differ between the real and synthetic DEMs. However, running the Method 2 variant of same procedure used to estimated $H_{\text {in }}$ on the appropriate 10 synthetic DEMs gives median $H_{r} / H_{\text {in }}$ values of $1.40 \pm 0.09(1 \sigma), \mathrm{a} \sim 20-60 \%$ height overestimation. This $\sim 40 \%$ figure for height overestimation is valid for the procedure's treatment of idealised Gaussian shapes of a distribution not yet proven to match reality, but even this is quite strong evidence of at least some overestimation of $H_{\text {in }}$. This is an indicator in favour of the first case where $H_{\text {in }}$ is overestimated and errors in recovery are similar for the real and synthetic data.

In summary, the simplest explanation for the similarity in the shapes of the recovered distributions, of $H_{\mathrm{r}}$ and $V_{\mathrm{r}}$, is therefore that the synthetic DEMs and drumlins well represent those digitised in Smith et al. (2009), at least in regard to the application of quantification techniques. It is also demonstrated that secure conclusions can be reached, with a little further analysis to understand discrepancies if necessary, even if input populations are probably not perfect. Namely, the approach using synthetic DEMs appears robust and of practical use.

\subsection{The cookie cutter method}


454 The nature of the errors affecting the cookie cutter is qualitatively predictable, without using 455 synthetic DEMs, by understanding the nature of the bi-cubic spline used. Consider a profile 456 (Fig. 14). Slopes immediately outside the drumlin dictate initial trajectories immediately inside 457 it, which the spline joins by varying gradient as smoothly as possible (e.g. Smith and Wessel, 458 1990). Small-scale high magnitude slopes in the measured DEM cause the interpolation on one 459 side to descend steeply whilst the other rises. $H$ is then overestimated: $H_{r}>H_{i n}$. Since $H$ is the 460 maximum height difference, a difference $>H_{\text {in }}$ need only occur once at any point for an 461 overestimate to occur. So, height overestimates are expected. $V$ is the sum of over-estimated (+) 462 and under-estimated (-) regions (shaded). So $V$ may be high, low, accurate or even negative 463 whilst height is positive. Overall, however, if noise creates random gradients at drumlins' 464 boundaries, errors randomly distributed about true values (e.g. Fig. 11b) are expected. The 465 numerical analysis is needed to build upon this qualitative understanding. Illustrative analyses 466 presented here determine the size of errors for key derived parameters (e.g. $\bar{H}, \bar{V})$ and whether 467 they are at all accurate. Some are not. Results derived using Methods 1 and 2 agree well (Figs. 468 10-13), giving confidence in such analyses. So, synthetic landscapes created with idealised 469 landforms within a real DEM can offer valuable insights into 3D landform extraction 470 methodologies.

\section{$\underline{6.2 \text { Other landform quantification techniques }}$}

474 The analyses performed with a variant on the cookie-cutter, using an un-tensioned spine, 475 illustrate that synthetic DEMs may also be used to compare landform quantification techniques. 476 Tensioning a bi-cubic spline reduces the amplitude of the extremes in its extrapolation. So errors 477 are expected to be larger for an un-tensioned spline. This is confirmed and quantified by the 478 numerical analysis. For the 1780 individual synthetic drumlins generated using Method 1 an un479 tensioned spline induces about twice $(\times 1.79)$ as much error as the tensioned spline, with standard 
deviations of the ratio $V_{\mathrm{r}} / V_{\text {in }}$ being 1.29 and 2.29 respectively. Figures for Method 2 are 2.96 and 5.01. So, the use of a tensioned spline by Smith et al. (2009) appears justified.

482

$\underline{6.3 \text { Sub-populations }}$

By linking input and recovered values for synthetic drumlins it is possible to examine claims in a depth that is not possible without synthetic DEMs. An analysis of the LGM and YD subpopulations in the study area demonstrates that it is possible to much better assess observations in the light of uncertainty in extracting drumlins' parameters. For instance, the apparently statistically significant difference in mean volume $\left(\Delta \bar{V}_{r}\right)$ between sub-populations of different ages (Smith et al., 2009), which may reflect glacial stress patterns (e.g. Rose, 1989), is demonstrated to be only $30-50 \%$ likely to exist in reality. Importantly, therefore, observations and scientific conclusions based upon them must remain in some doubt until errors are assessed. This assessment is significantly less practical where quantifications are done manually. Synthetic DEMs can also assess previous intractable issues such as the stationarity of the landscape with respect to the extraction of drumlins parameters. For instance, could the $\Delta \bar{V}_{r}$ of Smith et al. (2009) merely result from differences in the character of noise or hills in the LGM and YD areas and how this affects drumlin extraction? The analyses (Section 5.4) indicate not, which is reassuring for researchers interested in interpreting geomorphic signal and not noise. Other tests, e.g. to quantify the effect of errors in manual digitisation, are possible using the synthetic DEMs but the two done above serve to highlight the potential.

\section{Conclusions}

A novel way, using synthetic drumlins in a real DEM, is demonstrated to objectively test 3D landform quantification methods and probe their results in more depth than has previously been possible. Significant developments are i) the use of idealised drumlins, and ii) positioning them 
randomly with respect to the real noise and regional trends that cause the errors, which is the key

508 to allowing the quality of the extraction to be assessed. Creating synthetic drumlins using

509 height-width-length $(H-W-L)$ triplets extracted from measured DEM and digitised outlines

510 simplifies the implementation. The synthetic DEMs are demonstrably representative of the

511 observed landscape and circularity, the retrieval of input assumptions, is avoided.

184 drumlins in Central Western Scotland, and the application of the cookie cutter technique to

514 them (Smith et al., 2009), are used as a case study. From this, the following specific conclusions may be drawn.

Directly from the measured DEM and digitised outlines:

1. A suitable, representative $3 \mathrm{D}$ form of drumlins, in this area at least, is an elongated Gaussian.

Justified predominantly by the similarity in the form of $V$ and $H$ distributions recovered from the real and synthetic DEMs, about the proposed method:

2. Initial, somewhat naïve, methodologies to remove existing drumlins and approximate 'input' drumlin populations $(H-W-L)$ re-inserted into the synthetic DEMs are sufficient, i.e. the DEMs produced include drumlins that behave in a way closely representative of the real ones during the recovery of $H$ and $V$.

3. Orientations, $\theta$, and positions $(x, y)$ of synthetic drumlins randomly assigned, but according to observed distributions, are sufficient. 
Regarding analysis of Central Western Scotland area as in Smith et al. (2009):

5. $\quad V$ and $H$ for individual drumlins are both recovered poorly.

10. Acknowledgements

The NEXTMap DEM was kindly supplied by the British Geological Survey. We thank Niels Hovius, Katrien Van Landeghem, and an anonymous reviewer for their comments, which helped improve this work. Various figures in this manuscript and geometrical computations (e.g. splines) used the GMT software package (Wessel and Smith, 1998). 
561 Both methods described here to parameterise drumlins are new. Initially they locate the 'core' of 562 the drumlin $\left(C_{x y}\right)$ then place the longitudinal (long) and transverse (short) axes. This reverses 563 approaches such as that used by of Spagnolo et al. (2010) and is preferred here because they are 564 consistent with how one might assess drumlins in the field or manually from a map.

\section{A.1 Method 1: Central point}

568 Within drumlins, in general, height of the landform $\left(H_{\text {drumlin }}\right)$ increases as distance from the 569 planform edge of the drumlin increases. In plan view, therefore, the core of a drumlin might be 570 associated with a central point furthest from any edge: white circle, Fig. 3a. The smallest 571 distance between the centre of each cell in the $5 \mathrm{~m}$ by $5 \mathrm{~m}$ grid and the outline was computed. 572 Then the cell with the largest of these was selected as the centre, $C_{x y}$. This replicates one way in 573 which a drumlin's core may be manually located on a map.

$L$ is the length of the longest line running through $C_{x y}$ within the drumlin. To determine $L$, lengths $(l)$ of all lines starting at a digitised vertex, angle $\theta_{l}$ clockwise from north, were computed. Figure 6a illustrates this for an idealised drumlin. For real drumlins, the orientation of $L, \theta_{L}$, is usually tightly defined (Fig. 6b, white dot), and the shortest $l$ at about $90^{\circ}$ to $\theta_{L}$. $\theta_{S}$, the angle of the transverse axis, is therefore taken to be $\theta_{L}+90^{\circ}$. W is the length of this line. To

580 prevent any possible effects of the irregular vertex density present due to manual digitisation 581 additional vertices were placed, by linear interpolation, every $5 \mathrm{~m}$ along the outline. DEM after noise has been removed (Fig. 3b) and a linear interpolation between heights at the edges of the drumlin (dotted line, Fig. 4a). Height could also be defined perpendicular to the 
basal line, reducing it to $H \cos (\alpha)$ where $\alpha$ is the slope of the basal surface, but the effect is small

Method 1 does not estimate a basal surface from the DEM. $V$ is calculated from $H, W$ and $L$ (Eq.

A.1). 0.253 is the constant appropriate to the idealised Gaussian shape proposed.

$$
V=0.253 \times H \times W \times L
$$

Using parameter values derived using Method 2, there is close agreement $\left(r^{2}=0.8724, n=173\right)$ between the volumes estimated using Eq. A.1 and a grid-based calculation (Fig. 8b, grey and dashed lines), justifying this approach.

$C_{x y}$ estimates for Method 1 are not affected by topographic clutter. Its basal estimation is simple and transparent, but depends entirely upon heights at the drumlin's outline, and is thus affected by spatial error in digitisation (Fig. 4a). Parameters derived using Method 1, however, do not depend upon the $500 \mathrm{~m}$ wide median filter. The profile in Fig. 4a also highlights how height within a manually digitised landform may not reflect the conventional stoss-lee form. All 178 drumlins have $H>0$ using Method 1.

\section{A.2 Method 2: Highest point}

In the field, a drumlin's highest point can be located geographically, and might be considered to

608 lie over its core at $C_{x y}$. If significant, larger scale topographic trends underlie the drumlin they 609 should be accounted for. Accordingly, $C_{x y}$ may be estimated in a DEM as the location of the

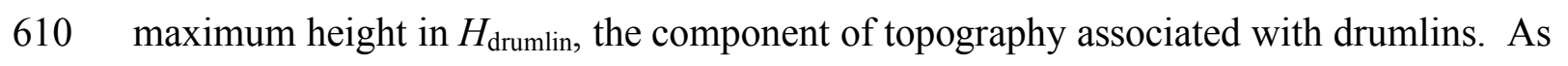
611 described in Section 3.1 median filters $(60 \mathrm{~m}, 500 \mathrm{~m})$ have been used to define $H_{\text {drumlin }}$. 
613 In Method $2 H$ was computed as the maximum height, and $V$ was calculated as the volume

614 associated with the component $H_{\text {drumlin }}$ for the area inside the landform. Again, $L$ and $W$ are

615 estimated as in Fig. 6. In Method 2, the median filters used to determine $C_{x y}$ are not affected by

616 digitisation errors, but the basal surface may be biased upwards (Fig. 4a) or the drumlin's upper

617 surface distorted by incompletely eliminated topographic noise. Method 2 therefore offers a

618 contrast to Method 1. 173 of 178 drumlins have $H>0$ using Method 2.

619

A.3 Parameter populations produced

The populations of parameters calculated by the two methods are similar (Fig. 5), and differences are readily explicable. For instance, $W$ (Fig. 5e) is larger for Method 1 because it is designed to locate the drumlin's centre as far as possible from the outline. $H$ is greater for the results of Smith et al. (2009) than either method because its heights are affected by clutter (e.g. trees), but this is expected. Lower volumes in Method 2 than are explained by the basal surface (500 m median filter) being raised (Fig. 3a). This is typical where 'normal' terrain not containing drumlins is in a minority, especially on slopes (Wessel, 1998). Volumes recovered by the Smith et al. (2009) lie between those of Methods 1 and 2, (Fig. 5b) suggesting that conclusions about $V$ may be safely drawn from observations seen in analyses of both methods.

631 Dominant orientations, $\theta_{L}$, indicated by steeper slopes in Figure 5a, are between $60-120^{\circ}$ and $240-300^{\circ}$ for both methods in good agreement with visual assessment of Figure 1c. Lastly, as expected of drumlin populations, there are more small drumlins than large ones in terms of $W, L$,

$634 \quad H$ and $V$, with the caveat that the smallest $W$ and $L$ are scarce.

\section{Appendix B: The Gaussian approximation used}

Height, $h_{x y}$ for a position $(x, y)$ within an elongate Gaussian form centred on $\left(x_{0}, y_{0}\right)$ of orientation

$\theta_{L}$ (Fig. 6) is, in Cartesian coordinates, described by Eqs. B.1-8. $H$ is the height of the drumlin. 
$639 L$ is length, and $W$ is width. $H_{G}$ is the full height of the Gaussian, and $H_{f}$ the fraction of this used

640 for the drumlin (e.g. 0.9 for the top 90\%).

641

642

643

Eq. (B.1) $\quad h_{x y}=H_{G} \exp \left[-\left(a\left(x-x_{0}\right)^{2}+2 b\left(x-x_{0}\right)\left(y-y_{0}\right)+c\left(y-y_{0}\right)^{2}\right)\right]-H_{G}+H$

Eq. (B.2) $\quad a=\frac{\cos ^{2} \phi}{2 \sigma_{L}}+\frac{\sin ^{2} \phi}{2 \sigma_{W}}$

644

Eq. (B.3) $\quad b=\frac{\sin 2 \phi}{4 \sigma_{L}^{2}}+\frac{\sin 2 \phi}{4 \sigma_{W}^{2}}$

645

Eq. (B.4) $\quad c=\frac{\sin ^{2} \phi}{2 \sigma_{L}^{2}}+\frac{\cos ^{2} \phi}{2 \sigma_{W}^{2}}$

646

Eq. (B.5) $\quad H_{G}=\frac{H}{H_{f}}$

647

Eq. (B.6) $\quad \sigma_{L}=\frac{L}{\sqrt{-8 \ln \left(1-H_{f}\right)}}$

648

Eq. (B.7) $\quad \sigma_{W}=\frac{W}{\sqrt{-8 \ln \left(1-H_{f}\right)}}$

649

Eq. (B.8) $\quad \phi=\theta_{L}-90$

650

\section{Appendix C: Synthetic DEM generation procedures}

652 In order to approximate spatial clustering an acceptance-rejection algorithm was used (e.g. Von

653 Neumann, 1951). Firstly, the spatial density of drumlins was computed (Fig. 9b). Trial

654 locations $(x, y)$ for drumlins were then generated at an even spatial density using two random

655 numbers, but these locations were rejected if i) a third random number generated with even

656 density in the range zero to one lay above the surface in Figure $9 \mathrm{~b}$ or ii) the proposed drumlin

657 footprint overlapped any existing footprints. This latter condition required that drumlins be

658 located in order of decreasing size, otherwise 'space problems' led to larger drumlins being

659 preferentially located in areas of lower observed drumlin density. $\theta$ values were created by a

660 standard method; random values ( 0 to 1 ) of the cumulative probability distribution of $\theta$ (Fig. 8a) 
were used, each of which corresponds uniquely to a $\theta$ value. The combined cumulative $\theta_{L}$

662 distribution of 10 populations $(n=1780)$ is visually indistinguishable from the observed 663 population (Fig. 8a).

664

665 gawk, using random() in stdlib.h was used to generate pseudorandom numbers. These are non666 cyclic over very long periods, sufficient at least to avoid interdependencies in the 'random' 667 numbers used in this study.

668

\section{Appendix D: Stochastic modelling}

670

The stochastic assessment used repeated random sub-division of the drumlin populations into

LGM and YD sub-populations of appropriate sizes. 100,000 iterations were used to generate the probability density functions for $\Delta \overline{\ln \left(V_{r}\right)}$ (Fig. 10). Three such distributions were generated, one for the original data and DEM (Smith et al., 2009), and one for each of the sets of 10 synthetic DEMs related to Methods 1 and 2. For the latter, one of the 10 DEMs was selected randomly each iteration. Implicitly, such indiscriminate assignment of drumlins to sub-populations employed the null hypothesis, $H_{0}$ : no difference exists. Using 100,000 iterations critical values (e.g. $\Delta \overline{\ln (V)}_{c r i t}$ ) at the $95 \%$ significance level are $5,000^{\text {th }}$ in lists of generated differences (e.g. $\left.\Delta \overline{\ln \left(V_{r}\right)}\right)$ ordered in descending magnitude: These are the levels that, if exceeded, occur rarely by chance and imply a statistically significant difference. $\Delta \overline{\ln \left(V_{r}\right)}$ of Smith et al. (2009) is 1.38 times that of the $95 \%$ critical value of its distribution, so instances where $\Delta \overline{\ln \left(V_{r}\right)}$ was more that $1.38 \times \Delta \overline{\ln (V)}_{\text {crit }}$ for the synthetic DEMs were taken as more extreme than those reported by Smith et al. (2009). The similarity in the shape of the distributions that makes this test valid is evidenced visually (Fig. 10), and by similar numbers of simulations containing more extreme differences than the threshold: 715 for the data of Smith et al. (2009), and 628 and 750 for Methods 1 and 2 respectively. Methods 1 and 2 use 178 and 173 drumlins respectively, 
687 bracketing the $n=175$ of Smith et al. (2009). Agreement between the methods, therefore,

688 indicates insensitivity to these variations. Consequently, no correction was made for the

689 difference in $n$.

690

$691 \quad$ References

692

693 Amundson, J. M., Iverson, N. R., 2006. Testing a glacial erosion rule using hang heights of

694 hanging valleys, Jasper National Park, Alberta, Canada. J. Geophys. Res. Earth Surface 111, art.

695 no. F01020.

696

697 Braun, J., Sambridge, M, 1997. Modelling landscape evolution on geological time scales: A new

698 method based on irregular spatial discretization. Basin Research 9, 27-52.

699

700 Brocklehurst, S. H., Wipple, K. X., 2004. Hypsometry of glaciated landscapes. Earth Surface

$701 \quad$ Processes and Landforms 29, 907-926.

702

703 Chase, C. G., 1992. Fluvial landscupting and the fractal dimension of topography.

704 Geomorphology 5, 39-57.

705

706 Cheng, Q. M., Agterberg, F. P., 1996. Multi-fractal modelling and spatial statistics Mathematical

707 Geology 28, 1-16.

708

709

Chorley, R. J., 1959. The Shape of Drumlins. J. Glaciol. 3, 339-344.

710

711 Clark, C., Hughes A., Greenwood, S., Spagnolo, M., Ng, F., 2009. Size and shape characteristics

712 of drumlins, derived from a large sample, and their associated scaling laws. Quart. Sci. Rev. 28, $713 \quad 677-692$. 
715 Densmore, A. L., Ellis, M. A., Anderson, R. S., 1998. Landsliding and the evolution of normal716 fault-bounded mountains. J. Geophys. Res. 103(B7), 15203-15219. doi:10.1029/98JB00510

718 Dziewonski, A., Hager, B., O’Connell, R., 1977. Large-scale heterogeneities in the lower 719 mantle. J. Geophys. Res. 82, 239-255.

721 Evans, I. C., 1987. A new approach to drumlin morphometry p119-130. In: J. Menzies and J. 722 Rose (Eds.), Drumlin Symposium. Balkema, Rotterdam.

Fowler, A. C., 2000. An instability mechanism for drumlin formation p307-319 In Deformation of Glacial Materials (Ed. Maltman, A. J.) Geol. Soc. Sepcial Publication 176.

Fowler, A. C., 2009. Instability modelling of drumlin formation incorporating lee-side cavity growth.

Proc. R. Soc A 465, 2681-2702.

Fowler, A. C., 2010a. The instability theory of drumlin formation applied to Newtonian viscous ice of finite depth Proc. R. Soc. A 466, 2673-2694.

Fowler, A. C., 2010b. The formation of subglacial streams and mega-scale glacial lineations Proc. R.

Gagnon, J. S., Lovejoy, S., Schertzer, D., 2006. Multifractal Earth topography Nonlinear Processes in Geophysics 5, 541-570. 
742 Harbour, J. M., 1992. Numerical Modeling of the development of U-shaped valleys by glacial 743 erosion. Geol. Soc. Am. Bull. 104, 1364-1375.

744

Hillier, J. K., Watts, A. B, 2004. "Plate-like" subsidence of the East Pacific Rise - South Pacific Superswell System J. Geophys. Res. 109, B10102 doi 10.1029/2004JB003041.

Hillier, J. K., 2008. Seamount detection and isolation with a modified wavelet transform Basin Research 20, 555-573.

Hillier, J. K., Smith, M., 2008. Residual relief separation: digital elevation model enhancement 752 for geomorphological mapping. Earth Surface Processes and Landforms 33, 2266-2276 doi: 10.1002/esp.1659

Hindmarsh, R. C. A., 1998. Drumlinization and drumlin-forming instabilities: viscous till mechanisms. J. Glaciology 44, 293-314.

Hollingsworth, S. E., 1931. The glaciation of western Edenside and adjoining areas and the drumlins of Edenside and the Solway Basin Quart. Journal Geol. Soc. London 87, 281-359.

Intermap (2004) Intermap product handbook and quickstart guide (v3.3).

Jamieson, S. S. R., Hulton, N. R. J., Hagdorn, M., 2008. Modelling landscape evolution under ice sheets. Geomorphology 97 91-108 of the India-Eurasia collisional system. Earth Planet. Sci. Lett. 236, 732-750. 
769 Kim, S. and Wessel. P., 2008. Directional median filtering for the regional-residual separation of

bathymetry. G3 9, Q03005 10.1029/2007GC001850

771

772

Lane, N. F., Watts, A. B., and Farrant, A. R, 2008. An analysis of Cotswold topography: insights

773 into the landscape response to denudational isostasy. J. Geol. Soc. 165, 85-103.

774

Lombardini, F., 2005. Analysis of non-Gaussian speckle statistics in high-resolution SAR images

IGARSS 2005: IEEE International Geoscience and Remote Sensing Symposium, Vols 1-8,

Proceedings 1337-1340

778

Malinverno, A., 1989. Testing linear models of seafloor topography Pure and Applied

780 Geohpysics 131, 139-155.

781

782

Mandelbrot, B., 1983. The Fractal Geometry Of Nature W. H. Freeman and Company, New 783 York.

784

Marova, N. A., 2002. Seamounts of the world ocean. Oceanology, 42(3), $409-413$.

Nolet, G., Allen, R., Zhao, Dapeng, 2007. Mantle plume tomography Chemical Geology 241,

Perron, J. T., Kirchner, J.W., Dietrich, W.E., 2008. Spectral signatures of characteristic spatial scales and nonfractal structure of landscapes J. Geophys. Res. 113, F04003.

793 Reed, B., Galvin, C. J., Millier, J. P., 1962. Some aspects of drumlin geometry Am. J. Sci 260, 
796 Rose, J., 1987. Drumlins as part of a glacier bedform continuum. 103-116 in Menzies, J., Rose.

797 J. (Eds.) Drumlin Symposium. Balkema, Rotterdam.

798

799 Rose, J., 1989. Glacial stress patterns and sediment transfer associated with the formation of 800 superimposed flutes. Sedimentary Geology 62, 151-176.

801

802 Rose, J., Smith, M.J., 2008. Glacial geomorphological maps of the Glasgow region, western 803 central Scotland. Journal of Maps v2008 doi:10.4113/jom.2008.1040

804

805 Saygin, E., Kennett, B. L. N., 2010. Ambient seismic noise tomography of Australian continent. 806 Tectonophysics 481, 116-125.

807

808 Schoof, 2007. Cavitation in deformable glacier beds. J. Appl. Math. 67, 163-1653.

809

810 Shaw, J., 1983. Drumlins formation related to inverted meltwater erosional marks. J. Glaciol. 29, $811 \quad 461-479$.

812

813 Sissons, J. B., 1967. The Evolution of Scotland's Scenery. Oliver and Boyd, Edinburgh. pp259

814 ISBN 0416840000.

815

816 Sithole, G., Vosselman, G., 2004. Experimental comparison of filter algorithms for bare-Earth

817 extraction from airborne laser scanning point coulds ISPRS. Journal of Photogrammetry and

818 Remote Sensing 59, 85-101

820 Smith, M. J., Clark, C., 2005. Methods for the visualisation of digital elevation models for

821 landform mapping. Earth Surface Processes and Landforms 30, 885-900 
823 Smith, M. J., Wise, S. M., 2007. Mapping glacial lineaments from satellite imagery: an

824 assessment of the problems and development of best procedure. Int. J. Applied Earth

825 Observation and Geoinformation 9, 65-78.

826

827 Smith, M. J., Rose, J., Booth, S., 2006. Geomorphological mapping of glacial landforms from

828 remotely sensed data: an evaluation of the principal data sources and an assessment of their

829 quality. Geomorphology 76, 148-165.

830

831 Smith, M. J., Rose, J., Gousie, M. B., 2009. The Cookie Cutter: A method for obtaining a

832 quantitative 3D description of glacial bedforms. Geomorphology 108, 209-218.

833

834 Smith, W., Wessel, P., 1990. Gridding With Continuous Curvature Splines in Tension.

835 Geophysics 55, 293-305.

836

837

Spagnolo, M., Clark, C. D., Hughes, A. L. C., Dunlop, P., Stokes, C., 2010. The planar shape of 838 drumlins. Sedimentary Geology 232, 119-131.

839

840 Sun, X., Rosin, P. L., Martin, R. M., Langbein, F. C., 2009. Noise analysis and synthesis for 3D

841 laser depth scanners. Graphical Models 71, 34-48.

842

Tate N. J., 1998. Estimating the fractal dimension of synthetic topographic surfaces. Computers 844 and Geosciences 24, 325-334.

846 Tate, N. J., 1998. Maximum entropy spectral analysis for the estimation of fractals in topography. Earth Surface Processes and Landforms 23, 1197-1217. 
849 Tomkin, J. H., 2009. Numerically simulating alpine landscapes: The geomorphological

850 consequences of incorporating glacial erosion in surface process models. Geomorphology 103,

$851 \quad 180-188$.

852

853 Tucker, G., Hancock, G. R., 2010. Modelling landscape evolution. Earth Surface Processes and

854 Landforms 35, 28-50.

855

856 Von Neumann, J, 1951. Various techniques used in connection with random digits. Monte Carlo

857 Methods. Nat. Bureau Standards 12, 36-38.

858

859 Weissel, J. K., Pratson, L. F., Malinverno, A., 1994. The length-scaling properties of topography.

860 J. Geophys. Res. 99, 13997-14012.

861

862 Wessel, P., 1997. Sizes and Ages of Seamounts Using Remote Sensing: Implications for

863 Intraplate Volcanism. Science 277, 802-805.

864

865 Wessel, P., 1998. An Empirical Method for Optimal Robust Regional-Residual Separation of

866 Geophysical Data. Mathematical Geology 30, 391-408.

867

868 Wessel, P., and Smith W. H. F., 1998. New, improved version of Generic Mapping Tools

869 released, EOS Trans. Amer. Geophys. U. 79(47), 579.

870

871 Wren, E. A., 1973. Trend Surface Analysis - A review. Canadian Journal of Exploration

872 Geophysics 9(1), 39-45.

873

874 Zhou, Q. M. and Lis, X. J., 2004. Analysis of errors of derived slope an aspect related to DEM

875 data properties. Computers and Geosciences 30, 369-378. 
878 Figure 1: Idealised profiles to illustrate the process used to create synthetic DEMs. There are 879 three 'components' (Hillier and Smith, 2008): Drumlins (dark grey shade) sit upon a regional 880 trend (dotted line). Both are overlain by 'clutter' or 'noise' (light grey shade). a) Upper and 881 lower surfaces of drumlin are estimated to define it, and it is removed (height subtracted). b) 882 Two Gaussian shaped drumlins are inserted (height added). Noise as Fig. 4a.

Figure 2: Location maps. a) Study area is located at $\left(4^{\circ} 28^{\prime} \mathrm{W}, 56^{\circ} 02^{\prime} \mathrm{N}\right)$, white circle: shown. b) DEM of a sub-region of the study area, with height displayed as greyscale, located in c): Woodland (W), Tree (T). c) Study area, with main geomorphic features of interest highlighted; drumlins (black outlines), rivers (grey), water (grey shade). A division between Younger Dryas (YD) and Last Glacial Maximum (LGM), white and stippled areas respectively, is also shown (Smith et al., 2006). Arrows indicate approximate ice flow trends in the LGM (Sissons, 1967) and YD (Rose, 1987). Map coordinates for b) and c) are of the British National Grid. $5 \mathrm{~m}$ grid.

Figure 3: Example of an inspection used to assess the ability of widths of median filter to separate noise, drumlins, and hills. Also, a drumlin illustrating the estimation of parameters $(x, y, L, W, \theta)$, and selection of primary axes, from its digitized outline.

a) Centre of drumlin (bold line) is at $x, y$ (white circle), determined by Method 1. Digitized outlines of other drumlins (thin lines) overlay the measured DEM. b) Computed axes (lines) overlie 'decluttered' topography to which a $60 \mathrm{~m}$ wide median filter has been applied. Arrows indicate directions of increasing distance along profiles in Figure 4. c) 'Clutter' removed i.e. difference between a) and b). d) $901 H_{\text {hills }}$ estimated using a 500 m median filter. Map coordinates are of the British National Grid. 
903 Figure 4: Height profiles across drumlin in Fig. 3. Profiles start from the directions $\theta_{L}$ and $\theta_{S}$

904 such that, assuming a conventional stoss-lee form, traditional interpretations of ice flow are as

905 indicted. Lines are: measured height (thin lines), estimates of the decluttered surface using $60 \mathrm{~m}$

906 wide median filter (thick black lines), linear interpolation between heights at the digitized edges

907 of the drumlin (dotted lines), $500 \mathrm{~m}$ wide median filter (grey lines). Grey boxes delimit the

908 drumlins. a) and b) are heights along the long and short axes, and c) and d) are normalized

909 profiles along the same axes.

910

911 Figure 5: Stacked (i.e. average) de-trended and normalized height profiles (black lines). Dashed

912 lines are $\pm 1 \sigma$ of height and dotted lines are \pm 2 standard errors of the individual profiles when

913 binned in 0.01 intervals of distance. Thick grey lines are Gaussian curves centred upon $x=0.5$.

914 Grey box is the bounding box for all drumlins. a) and b) are respectively for long and short axes

915 found using Method 1, whilst c) and d) are for Method 2. All profiles start from the directions $\theta_{L}$

916 and $\theta_{S}$. a) and b) $n=178$, c) and d) $n=173$.

917

918 Figure 6: Method of estimating parameters $\left(L, W, \theta_{L}, \theta_{s}\right)$ after $C_{x y}$ has been determined. a)

919 Idealised drumlin consisting of interpolation (black line) between digitized points (black dots),

920 with the centre $C_{x y}$ (open circle). At each point on the outline, $\theta$ and $l$ are calculated. b) $\theta$ and $l$

921 for all points on drumlin \#15 in Figure 2. $\theta_{L}$ (open circle) is $\theta$ for the largest li.e. $L$, and $\theta_{s}=\theta_{L}+$

$92290^{\circ}$ (cross): Compare to $\theta$ for the smallest $L$ (filled black circle). 'Ice flow' arrow indicates a

923 traditional interpretation of a conventional stoss-lee form.

Figure 7: Illustrative synthetic drumlin. a) Profile across the centre of drumlin. Drumlin interior (grey shade) and topography (solid line), are the top 90\% of a Gaussian curve (dashed line). b)

927 Plan view, grey shaded relief of drumlin, where black is zero. White line locates profile in a), 928 and dark lines trending N-S and E-W are given for reference. 
930 Figure 8: Cumulative distributions (cdfs) of parameters $\left(\theta_{L}, V, H, L, W\right)$. a) Orientation: Solid 931 black line is input values for the synthetics measured from non-Gaussian outlines in the real 932 DEM using Method $1(n=178$ of $H>0)$. This is overlain, indistinguishably, by the curve 933 combining the 10 synthetic DEMs generated from this input. Grey lines are for the individual

934 synthetic DEMs, and vertical bars are $\bar{y} \pm 2 \sigma$ of the mean. Dashed line is Method 2 ( $n=173$ of 935 $H>0$ ). b) and c) Volume and height: Solid black and black dashed lines as a), with black dotted 936 lines for the data of Smith et al. (2009). Dashed and dotted grey lines are values recovered by 937 the cookie cutter from synthetic DEMs created using Method 1 and 2 respectively, although they 938 mainly underlie the curves of the inputs in b). In b) solid grey line is an estimate of $H$, $W$ and $L$ 939 using Method 2, which is converted to $V$ using an idealised Gaussian geometry. d) and e) are 940 distributions for length and width, with lines as in a). For consistency with the data of Smith et 941 al. (2009) only $V>0$ are used throughout this figure. Smith et al. (2009) do not determine $\theta_{L}, L$, $942 W$ for comparison. Figure 9: Spatial distribution of drumlins. a) Observed distribution. b) Spatial density (i.e. \% of area) covered by drumlin, smoothed with a three kilometre wide boxcar filter, and displayed as a proportion of the highest density within the area. c) Illustrative spatial distribution from one of

94720 synthetic DEMs in study. d) Four synthetic DEMs neighbouring c) in generation process to 948 illustrate variability. Map coordinates are of the British National Grid.

950 Figure 10: Visualisation of method used to assess claims about differences in mean volume 951 between sub-populations. Probability density curves generated by stochastic analysis, $n=$ 952100,000 , for the observations of Smith et al. (2009) (dotted line), Method 1 (solid line), and 953 Method 2 (dashed line). Vertical bars are 95\% critical value and the difference observed by 
954 Smith et al. (2009). For simplicity, curves are scaled so that $95 \%$ critical values align with that

955 generated by the data of Smith et al. (2009).

956

957 Figure 11: Effectiveness of the extraction of drumlin $H$ and $V$. a) Histogram of individual 958 height recoveries, expressed as ratio of recovered height over input height, by Method 1. Arrow

959 is correct recovery. Circle is mean ratio, bar indicated $\pm 1 \sigma$. Grey bars represent all drumlins, 960 and black bars represent only large ( $L>500 \mathrm{~m}$ ) drumlins. b) as a) for $V$. c) and d) are as for a) 961 and b) for Method 2.

962

963 Figure 12: Reliability of recovered population parameters $\bar{H}$ and $\bar{V}$ for $n=173$. a) $\bar{H}$ for

964 Method 1. Input mean height (light grey bar) is significantly less than recoveries from the 10

965 synthetic DEMs (grey dots), whose mean and range $( \pm 2 \sigma)$ is displayed by the black dot and bar.

966 b) as a), except about $\bar{V}$ and shows recoveries consistent with input values. c) and d) are as for a) 967 and b), but for Method 2.

968

Figure 13: Comparison of recovered $V$ distributions. a) Distributions recovered as Smith et al. (2009) (dotted line), and using idealised Gaussian drumlins from synthetic DEMs generated from

971 Methods 1 and 2 (solid and dashed lines respectively). Means of the curves, $\bar{V}_{r}$ (solid vertical 972 line), are aligned to that of the extraction as Smith et al. (2009) by linear multipliers applied: 973 'scale factor'. c) Corresponding input distributions. Grey lines are for extractions of DEMs 974 created by Method 1 with errors of 1.0, 2.0, 3.0, 4.0 and 5.0 times those actually recovered, 975 'error multiplier': higher factors are lighter. b) and d) mean absolute misfit (i.e.

976 form $\left.\sum\left|x_{1}-x_{2}\right|\right)$ between curves for varied 'Scale Factor' and 'Error Multiplier' and the 977 recoveries as Smith et al. (2009). Best fit is white circle. Contour 25\% higher than the best fit 978 defines error ellipse (black line). Search increments 0.02. 
980 Figure 14: Schematic illustration of this action of a bi-cubic spline. Topography (solid lines) is

981 from Fig. 1, including observed noise from Fig. 4a. Arrows indicate gradients at the outline, and 982 dashed line is a minimum curvature (bi-cubic) interpolation $(\mathrm{T}=0)$ to estimate the basal surface 983 (dotted line). Tensioning the spline reduces the amplitude of deviations.

984 
Table 1: Percentage of 'good' estimates, with recovered values of $H$ and $V$ within $\pm 25 \%$ of actual values. Values in brackets use a variant of the cookie cutter recovery method using an untensioned spline.

\begin{tabular}{|l|l|l|}
\hline Method & \% of $V_{r} / V_{i n}$ & \% of $H_{r} / H_{\text {in }}$ \\
\hline 1 & $39.2[26.5]$ & $20.5[18.6]$ \\
\hline 2 & $47.6[34.3]$ & $25.8[23.0]$ \\
\hline
\end{tabular}

990

Table 2: Input and recovered population parameters. The mean and standard deviation $(\sigma)$ of

992 the estimates of $\bar{V}_{r}$ and $\bar{H}_{r}$ from 10 synthetic DEMs is reported in each case. Individual data 993 plotted on Fig. 12, grey dots. Note, $\sigma$ is not a standard error. Values in brackets use a variant of 994 the cookie cutter recovery method using an un-tensioned spline.

\begin{tabular}{|l|l|l|l|l|}
\hline Method & $\bar{V}_{i n}\left(\mathrm{~m}^{3}\right)$ & $\bar{V}_{r}\left(\mathrm{~m}^{3}\right)$ & $\bar{H}_{i n}(\mathrm{~m})$ & $\bar{H}_{r}(\mathrm{~m})$ \\
\hline 1 & 159,076 & $156,559 \pm 8,212(1 \sigma)$ & 6.82 & $12.54 \pm 0.28(1 \sigma)$ \\
& & {$[149,255 \pm 15,592]$} & & {$[13.15 \pm 0.26]$} \\
\hline 2 & 117,376 & $109,623 \pm 4,019(1 \sigma)$ & 6.43 & $11.76 \pm 0.23(1 \sigma)$ \\
& & {$[107,717 \pm 6,419]$} & & {$[12.23 \pm 0.24]$} \\
\hline
\end{tabular}

997 Table 3: Spatial effects upon extraction methodology, $E_{V}$, evaluated by comparing the difference 998 between input and recovered values in the LGM and YD populations. Subscripts denote volume 999 and height. Note that the standard deviation of $E, \sigma$, is the standard error of the differences 1000 between LGM and YD for individual DEMs. Square brackets are for the un-tensioned spline 1001 variant. 


\begin{tabular}{|l|l|l|}
\hline Method & $E_{V}\left(\mathrm{~m}^{3}\right)$ & $E_{H}(\mathrm{~m})$ \\
\hline 1 & $1,828 \pm 5,146(1 \sigma)$ & $1.34 \pm 0.22(1 \sigma)$ \\
& {$[6,272 \pm 5,756]$} & {$[1.28 \pm 0.23]$} \\
\hline 2 & $-5,094 \pm 2,862(1 \sigma)$ & $1.15 \pm 0.32(1 \sigma)$ \\
& {$[1,033 \pm 4,566]$} & {$[1.41 \pm 0.39]$} \\
\hline
\end{tabular}

1002

1003 
Figure 1

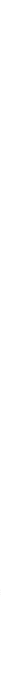

a) Original (idealised)

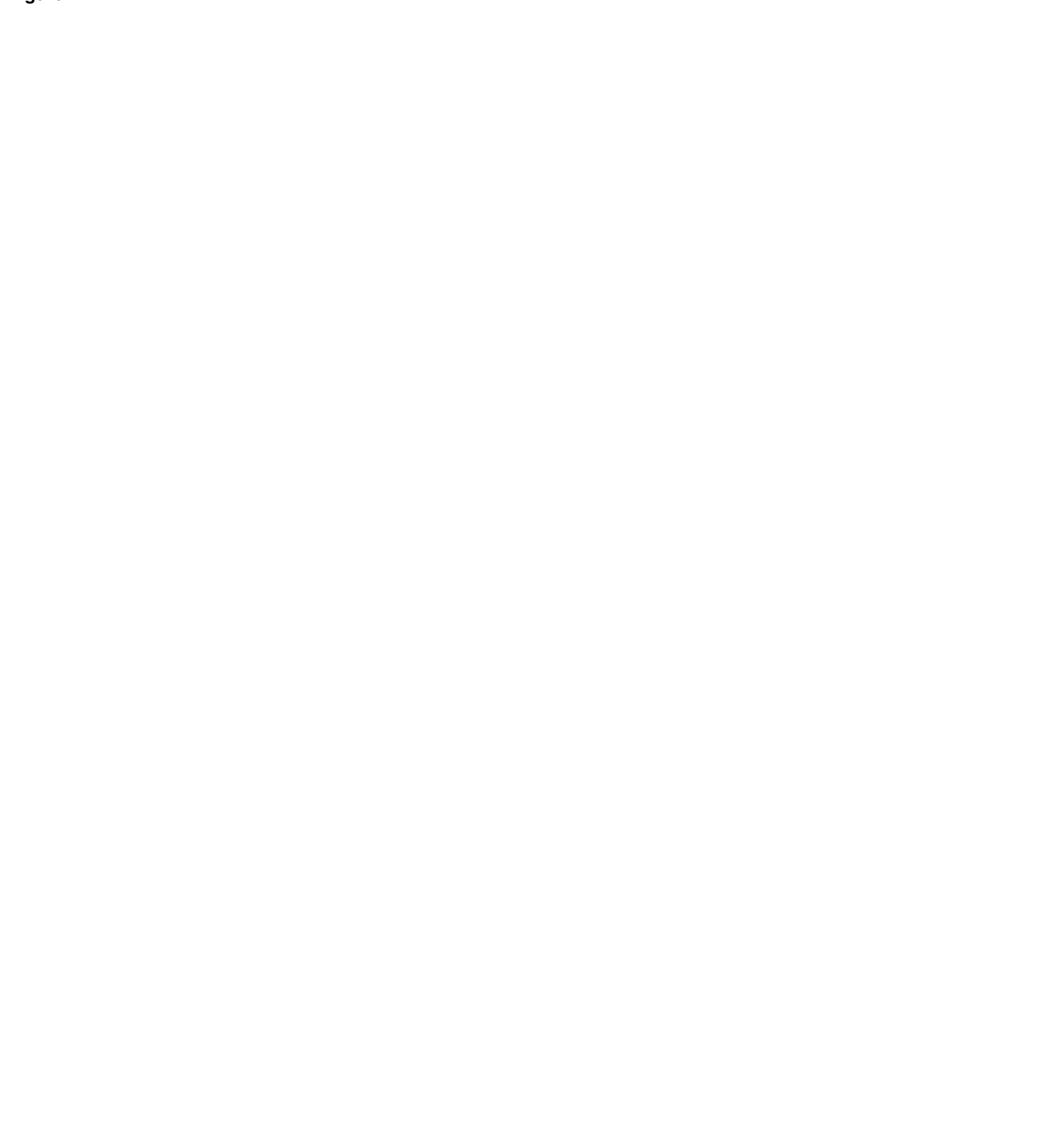



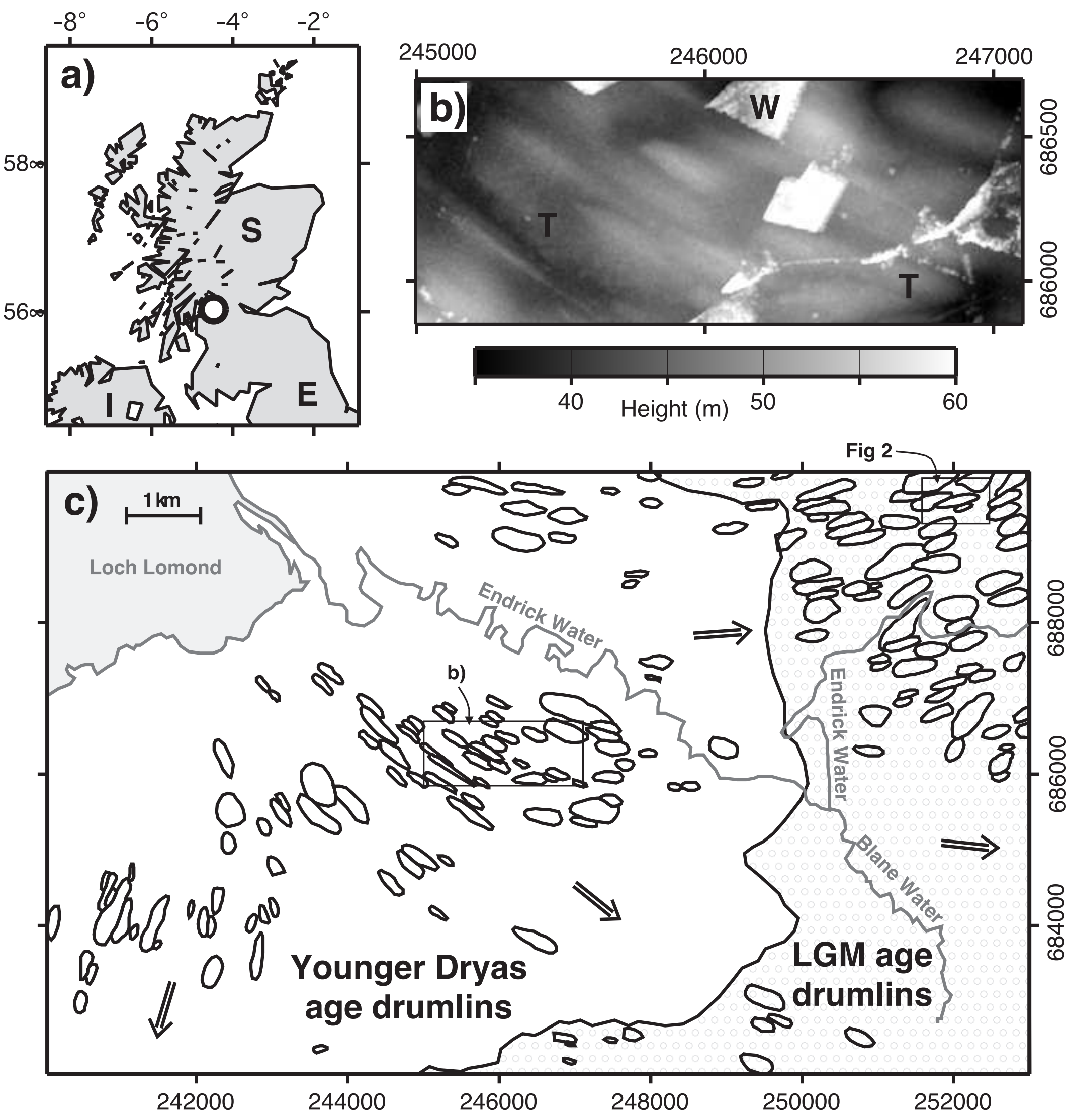

FIG 2 

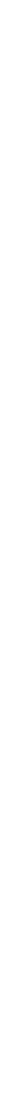

FIG 3 


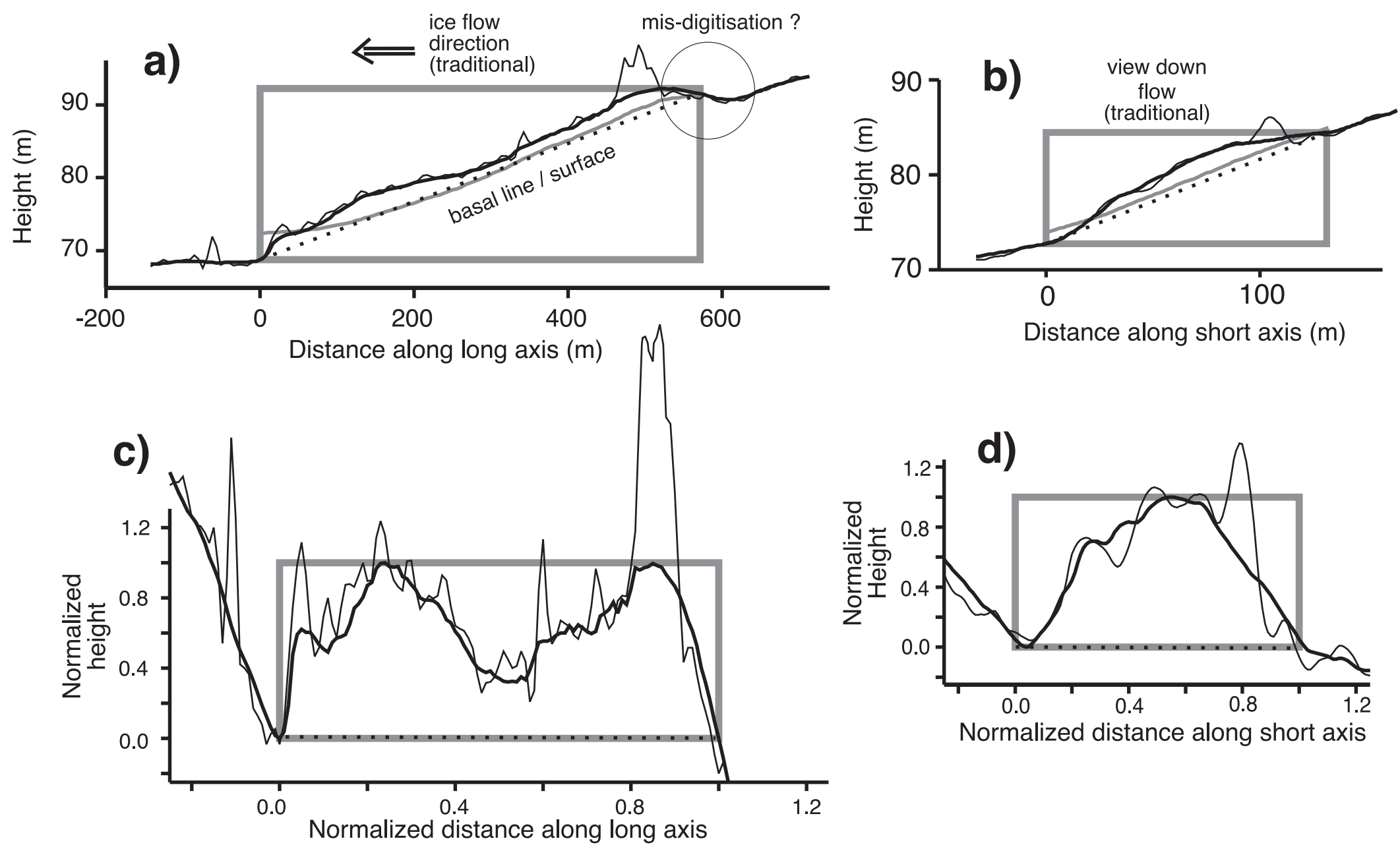

FIG 4 

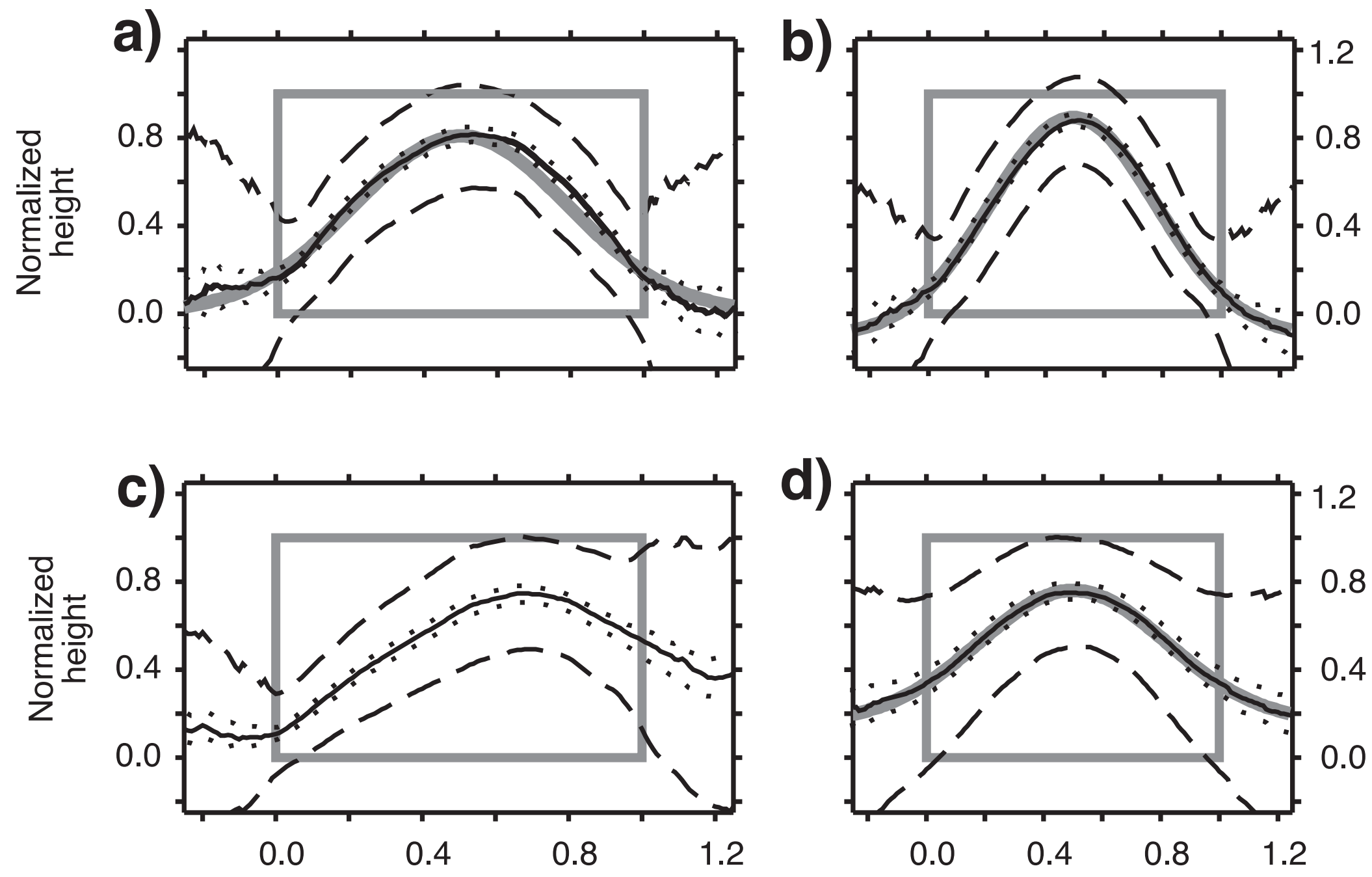

Normalized distance along long axis

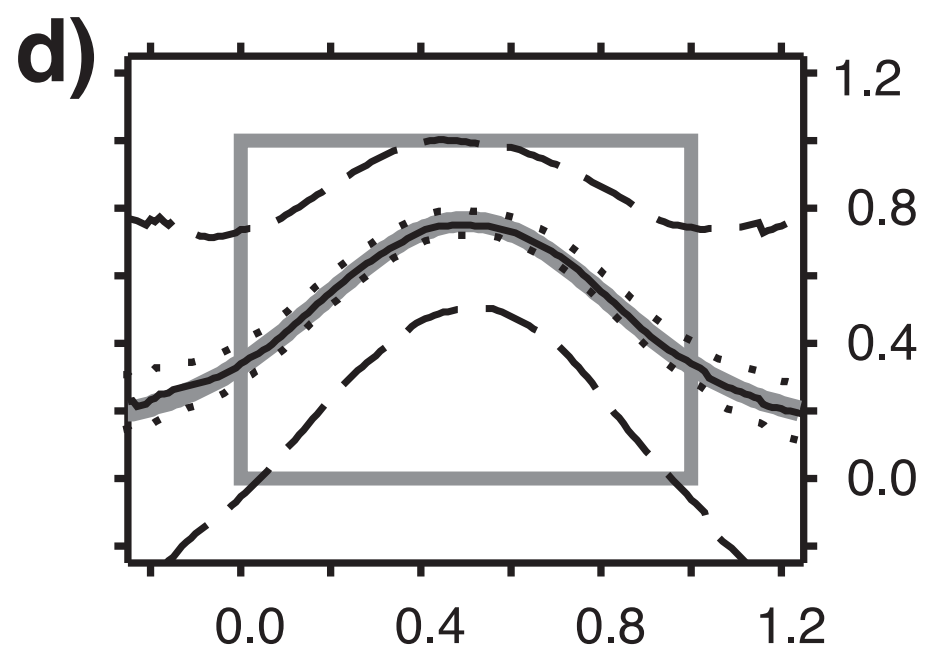

Normalized distance along short axis 
Figure 6
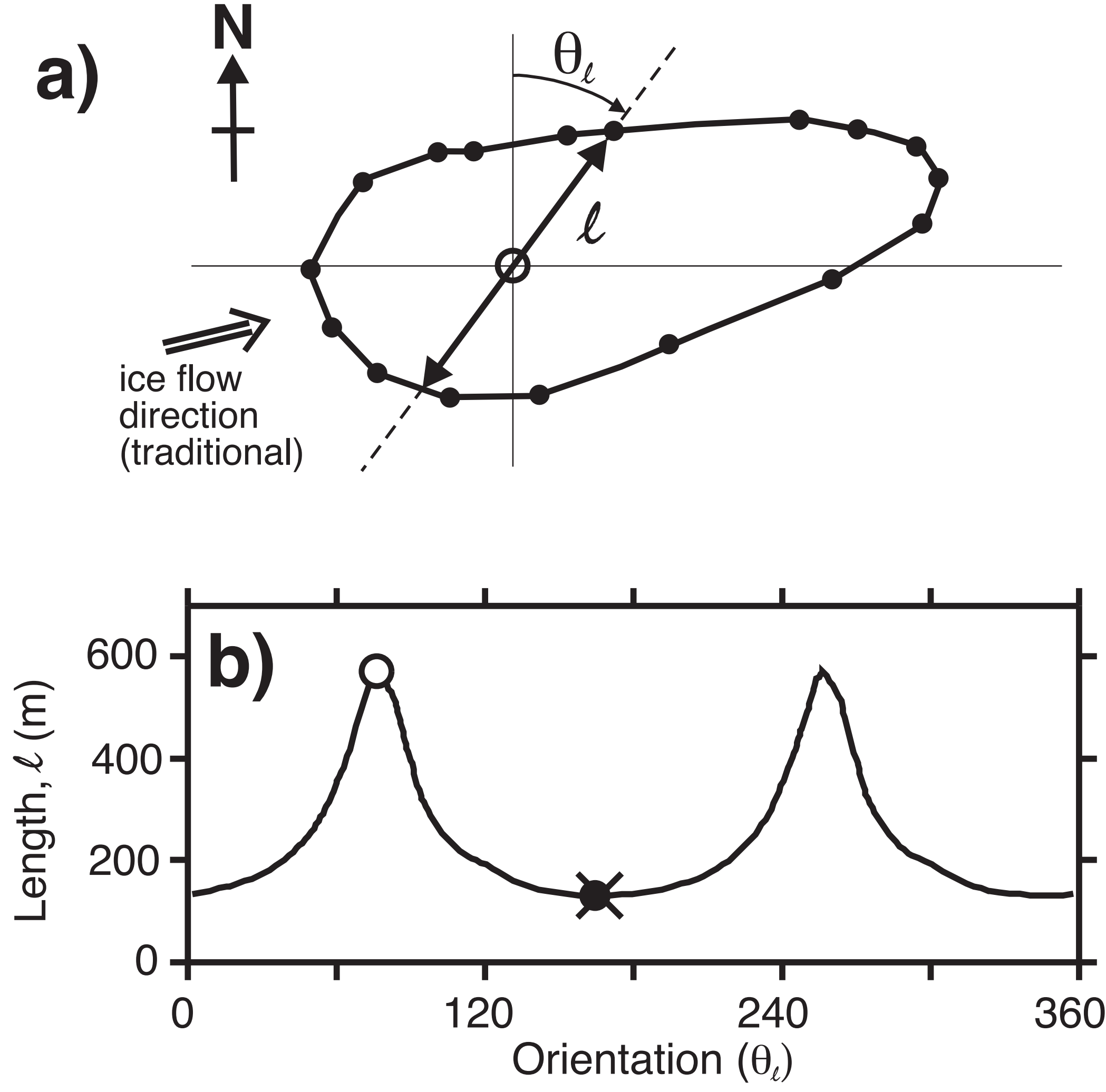

\section{FIG 6}


Figure 7

Click here to download high resolution image
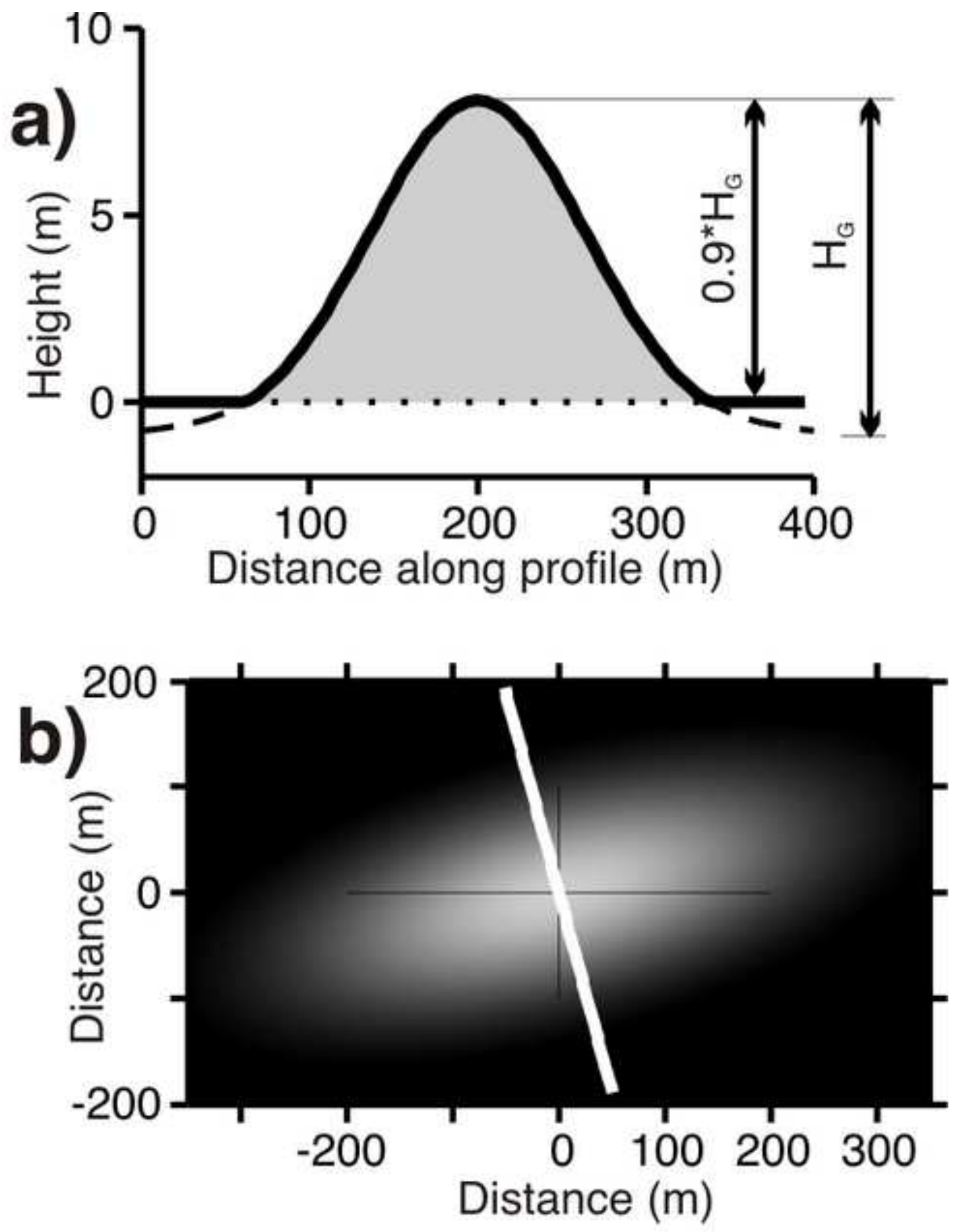
Figure 8
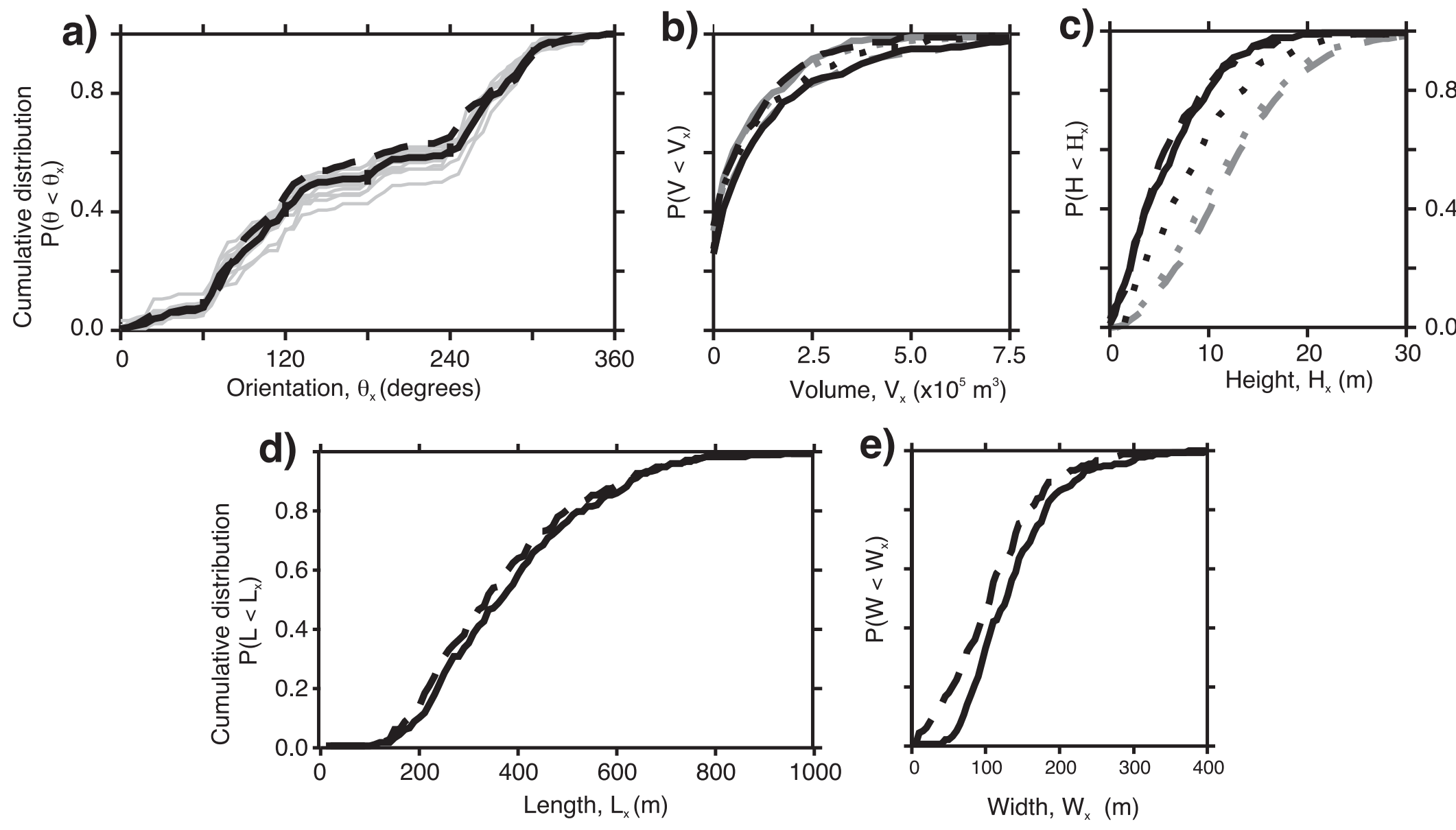

FIG 8 
Figure 10

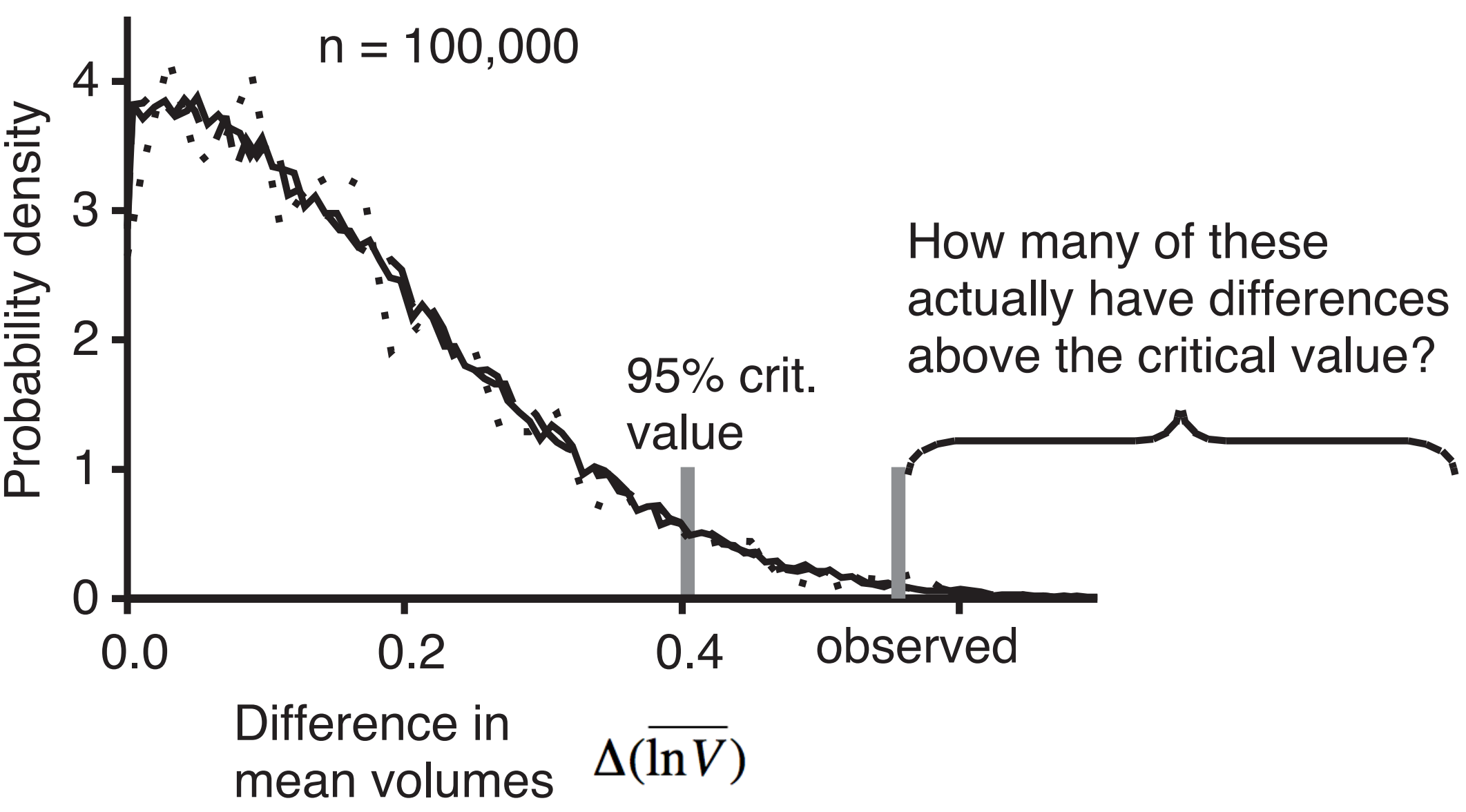

\section{FIG 10}


a)

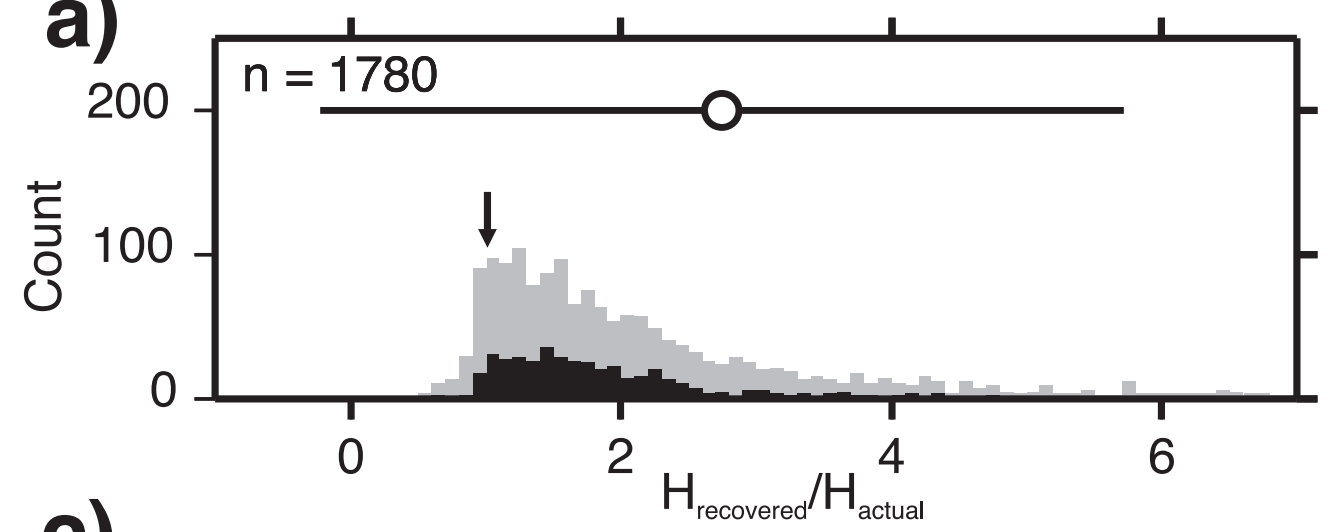

c)

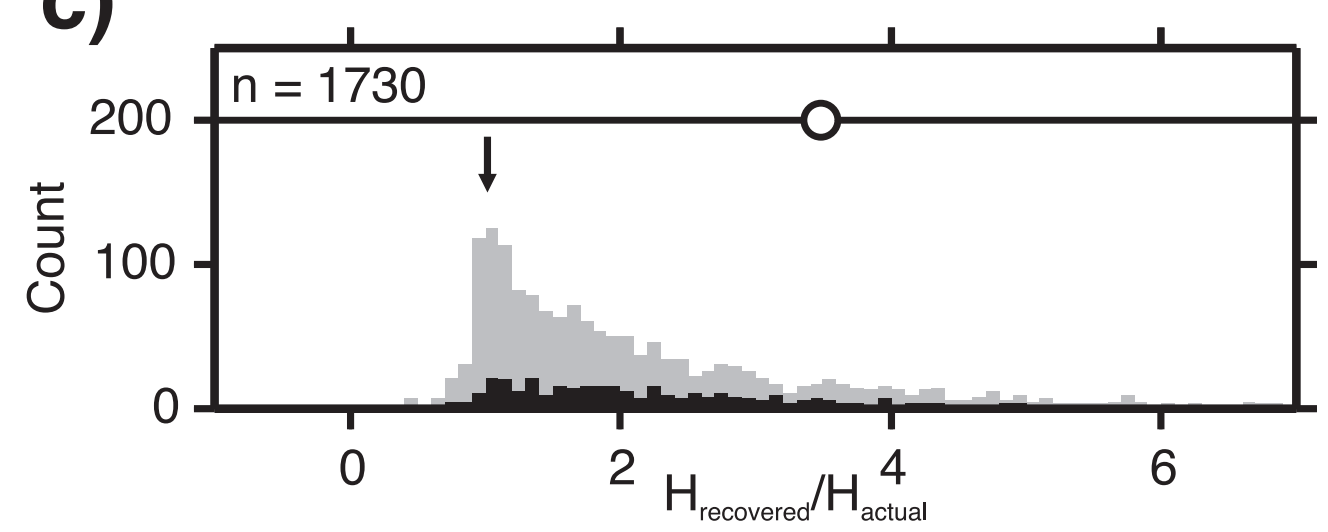

a)

actual
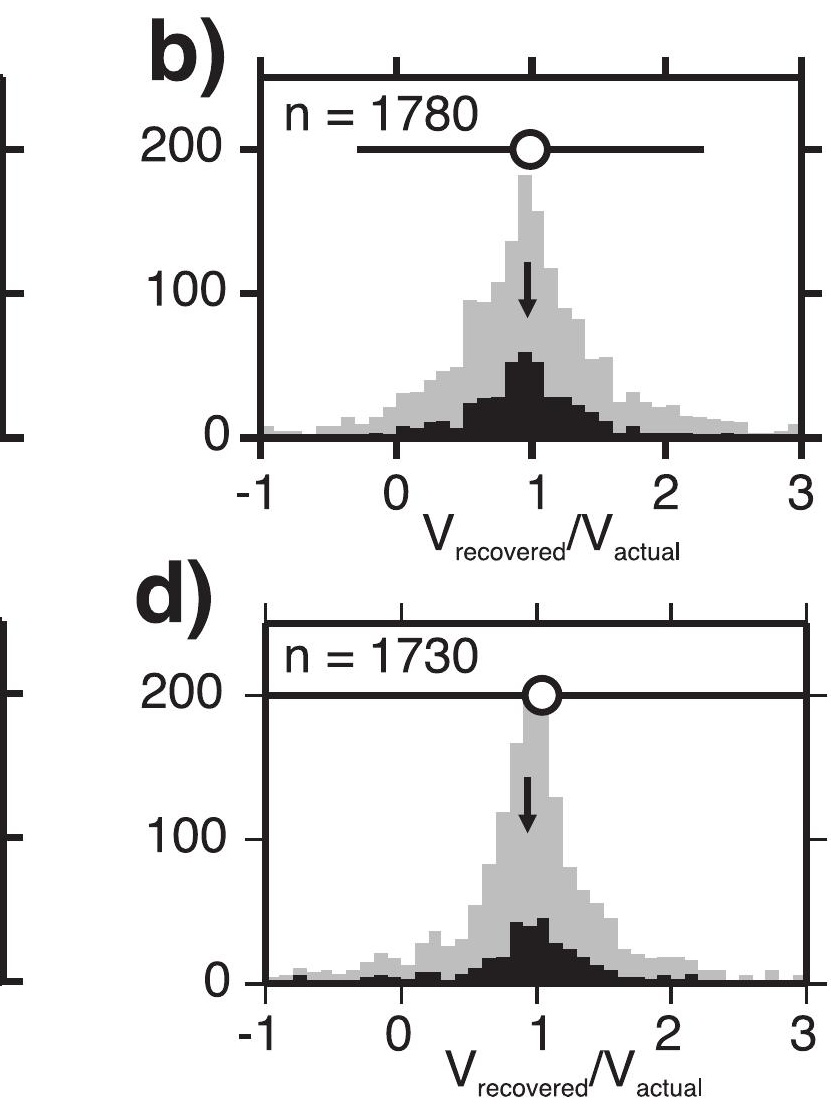
Figure 12

a)

b)
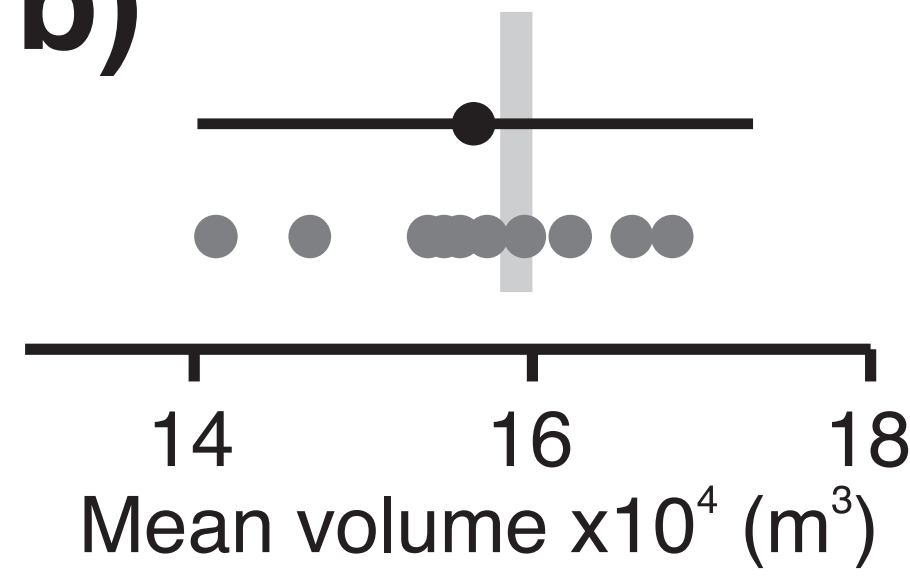

d)

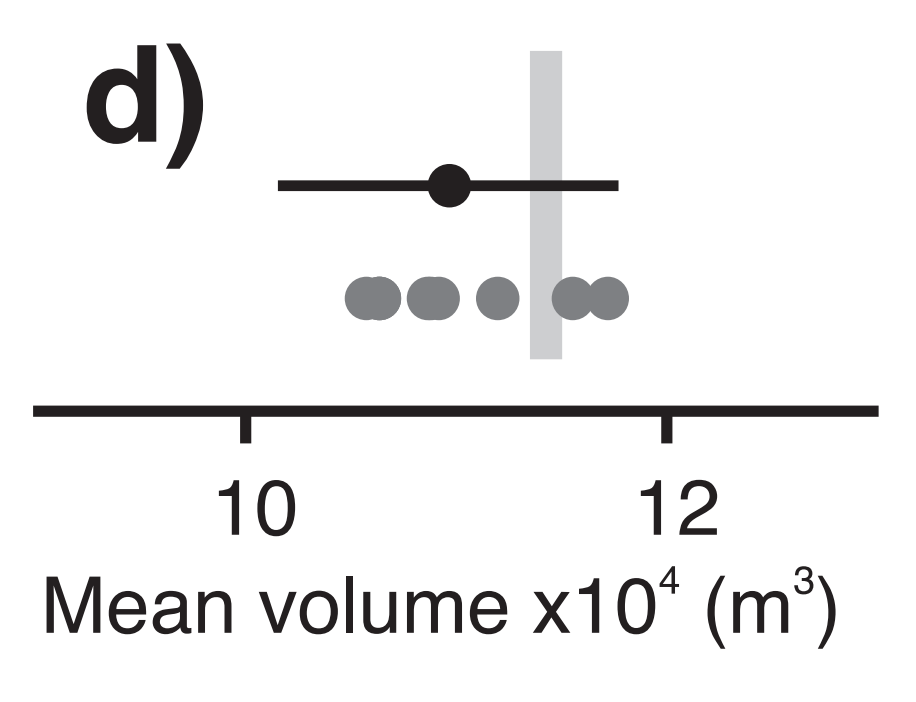

c)

Mean height $(\mathrm{m})$

15

5

10
eight $(\mathrm{m})$
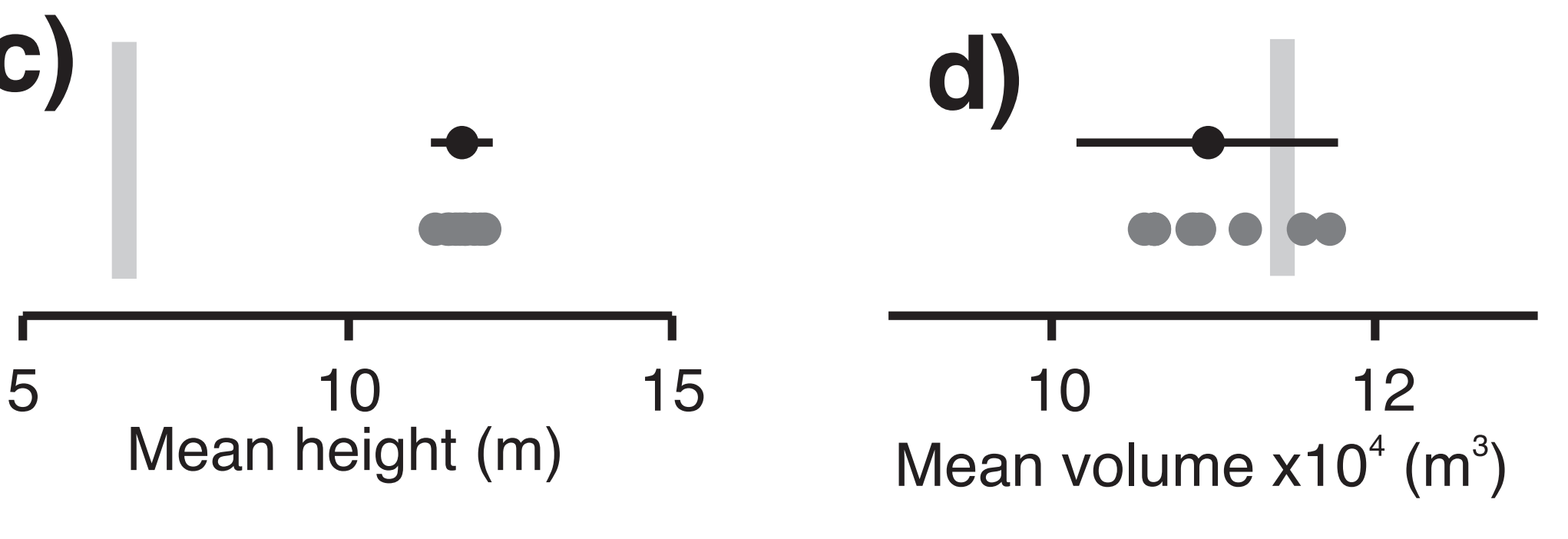

\section{FIG 12}

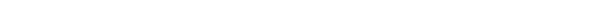



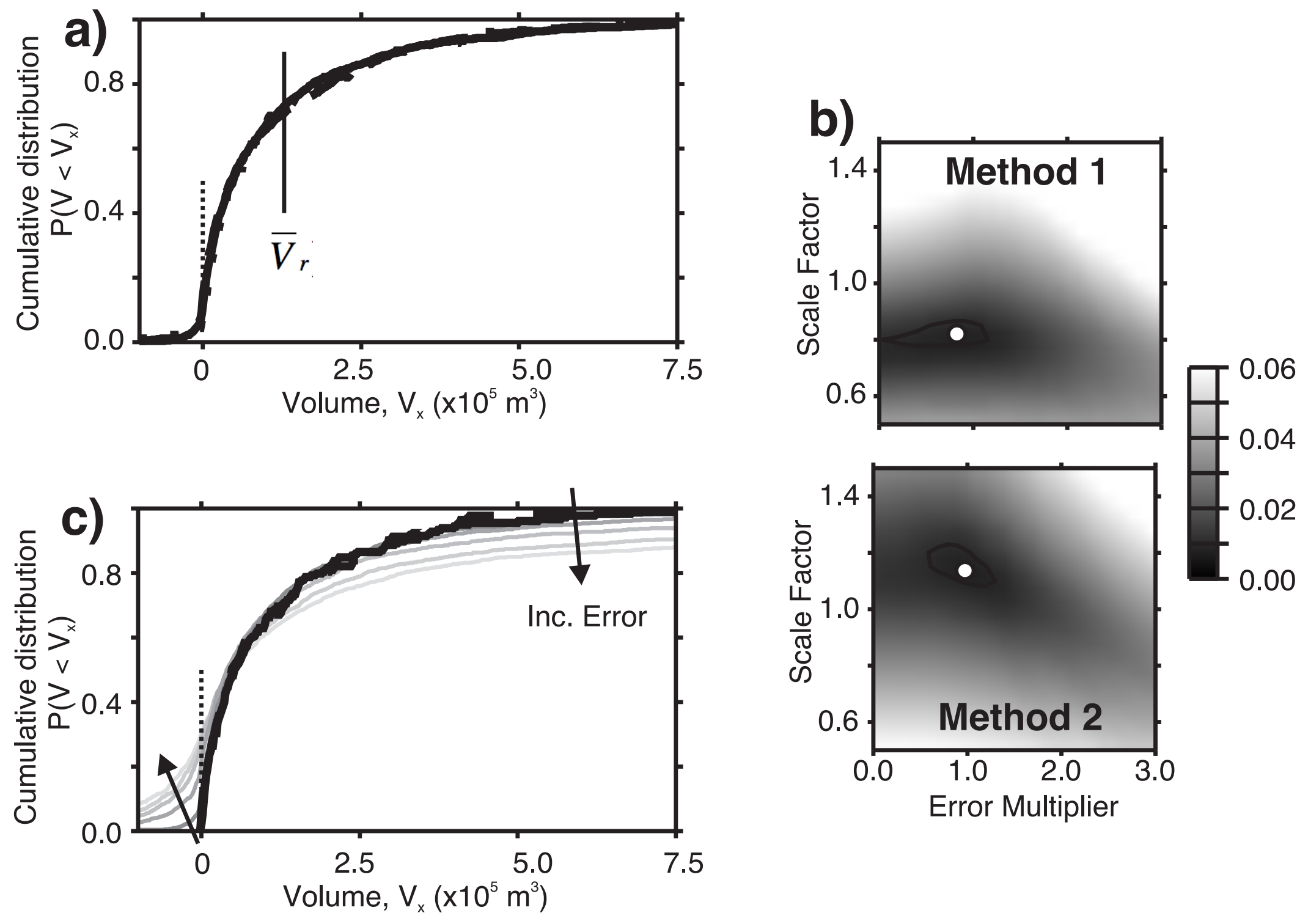

FIG 13 
Figure 14

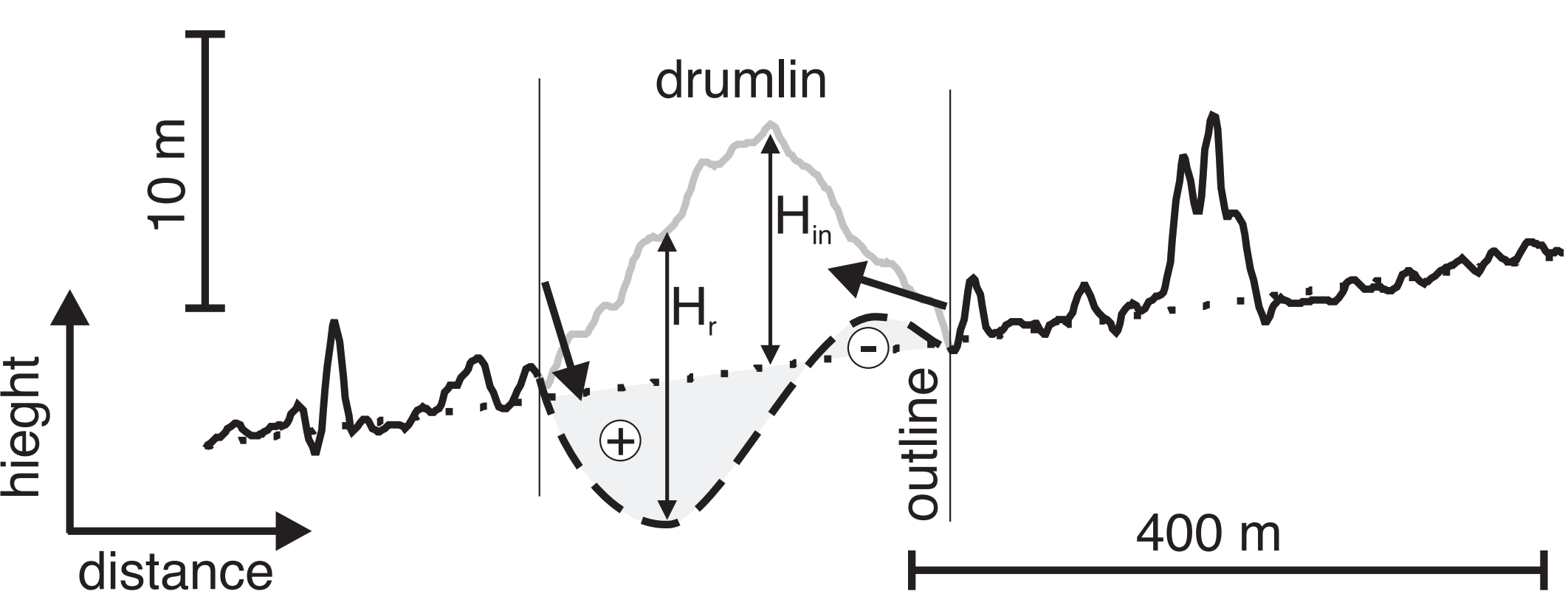

\section{FIG 14}
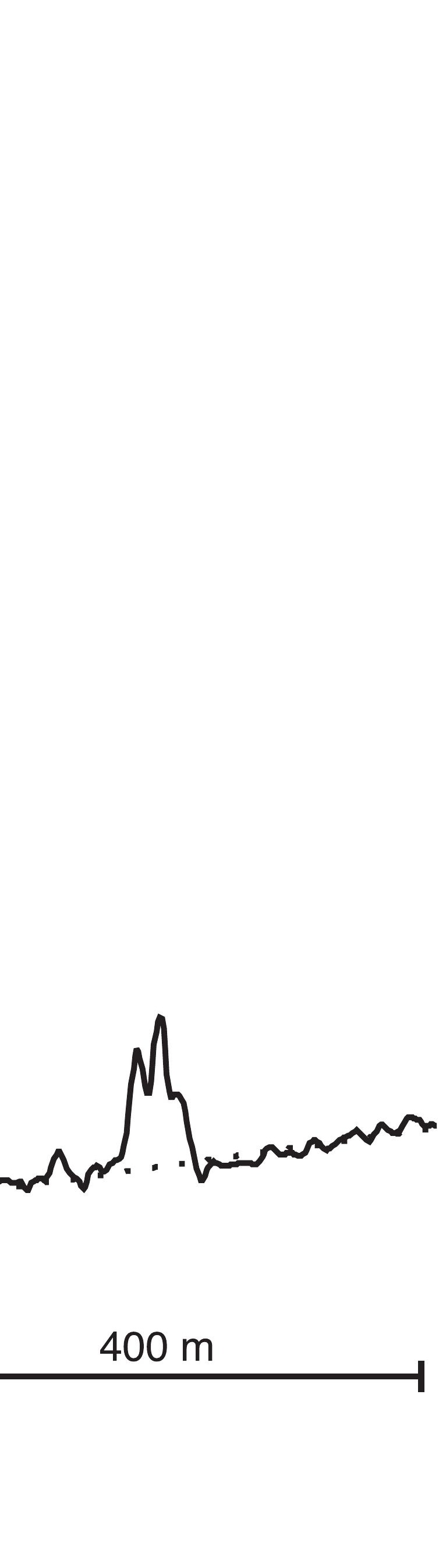